\title{
Dissociating embodiment and emotional reactivity in motor responses to artworks
}

Citation for published version (APA):

Finisguerra, A., Ticini, L. F., Kirsch, L. P., Cross, E. S., Kotz, S. A., \& Urgesi, C. (2021). Dissociating embodiment and emotional reactivity in motor responses to artworks. Cognition, 212, 1-15. [104663]. https://doi.org/10.1016/j.cognition.2021.104663

Document status and date:

Published: 01/07/2021

DOI:

10.1016/j.cognition.2021.104663

Document Version:

Publisher's PDF, also known as Version of record

Document license:

Taverne

Please check the document version of this publication:

- A submitted manuscript is the version of the article upon submission and before peer-review. There can be important differences between the submitted version and the official published version of record.

People interested in the research are advised to contact the author for the final version of the publication, or visit the DOI to the publisher's website.

- The final author version and the galley proof are versions of the publication after peer review.

- The final published version features the final layout of the paper including the volume, issue and page numbers.

Link to publication

\footnotetext{
General rights rights.

- You may freely distribute the URL identifying the publication in the public portal. please follow below link for the End User Agreement:

www.umlib.nl/taverne-license

Take down policy

If you believe that this document breaches copyright please contact us at:

repository@maastrichtuniversity.nl

providing details and we will investigate your claim.
}

Copyright and moral rights for the publications made accessible in the public portal are retained by the authors and/or other copyright owners and it is a condition of accessing publications that users recognise and abide by the legal requirements associated with these

- Users may download and print one copy of any publication from the public portal for the purpose of private study or research.

- You may not further distribute the material or use it for any profit-making activity or commercial gain

If the publication is distributed under the terms of Article $25 \mathrm{fa}$ of the Dutch Copyright Act, indicated by the "Taverne" license above, 


\title{
Dissociating embodiment and emotional reactivity in motor responses to artworks
}

\author{
Alessandra Finisguerra $^{\mathrm{a}, 1}$, Luca F. Ticini ${ }^{\mathrm{b}, 1}$, Louise P. Kirsch ${ }^{\mathrm{c}}$, Emily S. Cross ${ }^{\mathrm{d}}$, Sonja A. Kotz ${ }^{\mathrm{e}}$, \\ Cosimo Urgesi ${ }^{\mathrm{a}, \mathrm{F}, \text { " }}$ \\ ${ }^{a}$ Scientific Institute, IRCCS E. Medea, 33037 Pasian di Prato, Italy \\ ${ }^{\mathrm{b}}$ Division of Neuroscience and Experimental Psychology, School of Biological Sciences, The University of Manchester, M13 9PL Manchester, UK \\ ${ }^{\mathrm{c}}$ Institute for Intelligent Systems and Robotics (ISIR), Sorbonne Université, 75005 Paris, France \\ ${ }^{\mathrm{d}}$ Institute of Neuroscience and Psychology, University of Glasgow, G12 8QB Glasgow, UK \& Department of Cognitive Science, Macquarie University, NSW 2109, Sydney, \\ Australia \\ ${ }^{\mathrm{e}}$ Faculty of Psychology and Neuroscience, Maastricht University, 6200 MD Maastricht, the Netherlands \\ ${ }^{\mathrm{f}}$ Laboratory of Cognitive Neuroscience, Department of Languages and Literatures, Communication, Education and Society, University of Udine, 33100 Udine, Italy
}

\section{A R T I C L E I N F O}

\section{Keywords:}

Embodied aesthetics

Motor simulation

Artwork perception

Transcranial magnetic stimulation

Empathy

\begin{abstract}
A B S T R A C T
Perceiving art is known to elicit motor cortex activation in an observer's brain. This motor activation has often been attributed to a covert approach response associated with the emotional valence of an art piece (emotional reaction hypothesis). However, recent accounts have proposed that aesthetic experiences could be grounded in the motor simulation of actions required to produce an art piece and of the sensorimotor states embedded in its subject (embodied aesthetic hypothesis). Here, we aimed to test these two hypotheses by assessing whether motor facilitation during artwork perception mirrors emotional or motor simulation processes. To this aim, we capitalized on single pulse transcranial magnetic stimulation revealing a two-stage motor coding of emotional body postures: an early, non-specific activation related to emotion processing and a later action-specific activation reflecting motor simulation. We asked art-naïve individuals to rate how much they liked a series of pointillist and brushstroke canvases; photographs of artistic gardens served as control natural stimuli. After an early (150 ms) or a later (300 $\mathrm{ms}$ ) post-stimulus delay, motor evoked potentials were recorded from wrist-extensor and finger muscles that were more involved in brushstroke- and pointillist-like painting, respectively. Results showed that observing the two canvas styles did not elicit differential motor activation in the early time window for either muscle, not supporting the emotional reaction hypothesis. However, in support of the embodied aesthetic hypothesis, we found in the later time window greater motor activation responses to brushstroke than pointillist canvases for the wrist-extensor, but not for the finger muscle. Furthermore, this muscle-selective facilitation was associated with lower liking ratings of brushstroke canvases and with greater empathy dispositions. These findings support the claim that simulation of the painter's movements is crucial for aesthetic experience, by documenting a link between motor simulation, dispositional empathy, and subjective appreciation in artwork perception.
\end{abstract}

\section{Introduction}

What drives a person to approach an artwork in a museum, and then spend some time beholding that particular piece? The aesthetic experience represents a unique case in human perception as perceiving an object is not inherently linked to act on it, but to the appreciation of its properties (Chatterjee \& Vartanian, 2014; Kirsch, Urgesi, \& Cross, 2015; Sarasso et al., 2019). From a neuroscientific perspective, the aesthetic experience can be conceived as the event allowing a beholder to "perceive-feel-sense" an artwork (Di Dio \& Gallese, 2009), and involves

\footnotetext{
Abbreviations: CSE, corticospinal excitability; EMG, electromyography; FDI, first dorsal interosseous; ECR, exotensor carpi radialis; MEPs, motor evoked potentials; PT, Perspective Taking; rMT, resting motor threshold; spTMS, single pulse transcranial magnetic stimulation.

* Corresponding author at: Department of Languages and Literatures, Communication, Education and Society, University of Udine, Via Margreth, 3, I-33100 Udine, Italy.

E-mail address: cosimo.urgesi@uniud.it (C. Urgesi).

1 These authors equally contributed to this work.
} 
a rich interplay between brain networks linked to perception, reward, and cognition (Chatterjee \& Vartanian, 2014; Di Dio \& Gallese, 2009; Kirsch, Urgesi, \& Cross, 2015; Pearce et al., 2016). However, since the very first studies that used human neuroscience methods to begin to map aesthetic experiences (Kawabata \& Zeki, 2004; Vartanian \& Goel, 2004) it has been shown that viewing an artwork also involves activation of the beholder's motor areas next to sensory and reward areas. It is unclear, however, whether this motor activation reflects a non-specific emotional response to a piece of art or whether it rather mirrors the simulation of the sensorimotor states embedded in art.

A pioneering neuroimaging study of art perception showed that, while the reward network activates more strongly when viewing pleasant paintings, the motor cortex was shown to be more strongly activated when participants viewed paintings they rated as ugly, compared to those rated as pleasant or neutral (Kawabata \& Zeki, 2004). A similar pattern of motor activation was found during the observation of human-form sculptures rated as ugly or pleasant (Di Dio, Macaluso, \& Rizzolatti, 2007). Equally, a magnetoencephalography study (CelaConde et al., 2009) reported, for a 300-700 ms post-stimulus interval, greater activation of sensorimotor cortices in response to artworks rated as more beautiful than less beautiful. The involvement of the motor cortex in artwork perception was ascribed by these earlier neuroimaging studies to a covert emotional response to a piece of art. This emotional reactivity was deemed to prepare the observer to respond to a stimulus either to avoid an unpleasant/ugly or to approach a pleasant/beautiful one (Armony \& Dolan, 2002; Kawabata \& Zeki, 2004). Accordingly, several studies have highlighted that the basic emotional states of pleasure (leading to an approaching response) and pain (leading to an avoiding response) play a major role in aesthetic experience (Xenakis \& Arnellos, 2015; Xenakis, Arnellos, \& Darzentas, 2012).

Crucially, in contrast to the emotional reaction account, motor activation in artwork perception has been reframed in an embodied simulation account of aesthetics (Freedberg \& Gallese, 2007), which claims that aesthetic experience is grounded in the simulation of actions, emotions, and bodily sensations induced by art. In this account, the engagement of a viewer's motor system facilitates the simulation of the sensorimotor correlates of actions depicted on a canvas and/or of the artist while producing an artwork (e.g., the actions/brushstrokes required to produce a painting or sculpture, or the human body's motions involved in dancing or acting; Heimann et al., 2019). This motor simulation underpins an empathic response toward a piece of art, ultimately contributing to its aesthetic appreciation (Kirsch, Urgesi, \& Cross, 2015; Ticini, Urgesi, \& Calvo-Merino, 2015). In line with this view, singlepulse transcranial magnetic stimulation (spTMS; Battaglia, Lisanby, \& Freedberg, 2011) electroencephalography (Sbriscia-Fioretti, Berchio, Freedberg, Gallese, \& Umiltà, 2013; Umilta, Berchio, Sestito, Freedberg, \& Gallese, 2012), and neuroimaging (Lutz et al., 2013) studies have shown greater activation of fronto-parietal areas, known to match action execution with action observation (Rizzolatti \& Craighero, 2004), during the observation of paintings as compared to modified, non-artistic stimuli. Furthermore, it has been shown that mimicking the emotional expression depicted in Renaissance and Baroque portraits increases their aesthetic appreciation, in particular in those individuals experienced in art appreciation while also reporting higher disposition to take others' perspective and to identify with others (Ardizzi et al., 2020). Taken together, these findings suggest a tight link between simulation, empathy, and an observer's aesthetic experience (Gernot, Pelowski, \& Leder, 2018).

Further compelling evidence in favor of embodiment in aesthetic appreciation has come from a study by Leder and colleagues (Leder, Bär, \& Topolinski, 2012), reporting that participants' aesthetic appreciation of paintings was enhanced when they were asked to perform actions that matched the artist's painting style. In this study, participants rated how much they liked pointillist-style (Neo-Impressionist) paintings and brushstroke-style (Post-Impressionist) paintings before, during, and after performing either repetitive pointillist-like stippling or brushstroke-like stroking movements. The results showed that participants preferred pointillist- over brushstroke-style paintings in stippling movements and brushstroke- over pointillist-style paintings in stroking movements. The authors ruled out that simply viewing the hand movements might have led to a style matching or congruency effect as the participant's hand was hidden from view. However, if executed and observed actions would conflate in a matching sensorimotor representation (Prinz, 1997), the simulation of an artist's style should be boosted by the observation and not only execution, of congruent movements. This was tested in a subsequent study (Ticini, Rachman, Pelletier, \& Dubal, 2014), where participants were trained to execute brushstrokes with either stippling (using a precision grip) or stroking (using a power grip) movements before asking them to provide liking ratings for a series of pointillist-style canvases. The presentation of each canvas was preceded by a static image of a hand holding a paintbrush with a precision or a power grip, thus priming a pointillist- or a brushstroke-like painting style, respectively. The results showed that the participants' liking ratings of paintings increased after the presentation of action primes that matched the artist's style, further suggesting that the activation of congruent motor representations in action observation boosts an observer's aesthetic appreciation of a piece of art.

However, these behavioral studies cannot tell us anything about the extent to which action priming modulates the response of the observer's motor cortex to artworks. Nor can they disentangle whether these behavioral priming effects truly reveal the contribution of motor simulation to aesthetic appreciation or instead reflect general emotional responses to the observation of action outcomes (i.e., a painted canvas) that are congruent with an executed (Leder et al., 2012) or observed (Ticini, Rachman, Pelletier, \& Dubal, 2014) movement. In other words, it is possible that viewing or executing actions (e.g., pointillist-like painting movements) may influence a more favorable attitude toward congruent (e.g., pointillist-style canvases) than incongruent (e.g., brushstroke-style canvases) stimuli. This would not necessarily reflect that aesthetic experience is inherently linked to simulation of the painter's movements. Indeed, recent evidence suggests that viewing stimuli of negative or positive valence differentially modulates the aesthetic appreciation of subsequently presented abstract forms or body postures (Boukarras, Era, Aglioti, \& Candidi, 2020; Era, Candidi, \& Aglioti, 2015, 2019). Similarly, viewing pictures of everyday life situations with positive or negative valence or of emotional body language triggers motor activation in observers (Borgomaneri, Gazzola, \& Avenanti, 2015; Tamietto et al., 2009) as does viewing artworks (Battaglia, Lisanby, \& Freedberg, 2011). Thus, emotion processing and aesthetic experience are intrinsically intertwined at both neural and behavioral levels (Kirsch, Urgesi, \& Cross, 2015), leaving open the question whether motor responses to a piece of art reflect simulative action representations or general emotion reactivity.

Previous studies (Borgomaneri et al., 2015; Naish, Houston-Price, Bremner, \& Holmes, 2014) have demonstrated that activations of an observer's motor cortex in response to motor simulation and emotion processing occur in distinct spatio-temporal profiles. By combining spTMS with electromyographic recording of motor evoked potentials (MEPs), it is possible to record the level of corticospinal excitability (CSE) of specific muscles at precise delays after stimulus presentation (Amoruso \& Finisguerra, 2019; Avenanti, Candidi, \& Urgesi, 2013; Fadiga, Craighero, \& Olivier, 2005). The literature indicates that action simulation facilitates CSE mainly in the muscles that are used during the execution of observed movements (Naish, Houston-Price, Bremner, \& Holmes, 2014; Urgesi, Candidi, Fabbro, Romani, \& Aglioti, 2006) around $200 \mathrm{~ms}$ post-stimulus presentation (Lepage, Tremblay, \& Théoret, 2010; Naish, Houston-Price, Bremner, \& Holmes, 2014; Ubaldi, Barchiesi, \& Cattaneo, 2013). Conversely, emotion-related motor responses tend to occur earlier (less than 150-200 ms after stimulus presentation) and are void of muscle specificity (Borgomaneri et al., 2015; Tamietto et al., 2009). Specifically, measuring CSE at different timepoints after the presentation of body postures, Borgomaneri et al. 
(2015) confirmed a two-stage processing of emotional body postures in the motor cortex. At $150 \mathrm{~ms}$, they found an emotion-specific CSE modulation for stimuli that implied an emotional compared to a neutral movement. Conversely, at $300 \mathrm{~ms}$ they found an action-specific CSE modulation for stimuli implying a movement (either emotional or neutral) as compared to static stimuli. Here, we capitalized on this dissociation between early (generalized and related to emotion processing) and later (action-specific and reflecting simulative motor mapping) CSE modulations to test whether the activation of the motor cortex during artwork perception reflects the emotional reaction to an artwork or rather the motor simulation of the acts that are required to produce the piece of art. Namely, we aimed to test at which processing stage and at which level of action-specificity the aesthetic value of a stimulus influences motor cortex activity.

To this aim, we measured CSE during the observation of canvases painted with a pointillist- or a brushstroke-like style or of photographs of historical gardens (control stimuli) while art-naïve participants rated how much they liked each painting/photographs. To dissociate early from later activations, spTMS-evoked MEPs were measured at an early $(150 \mathrm{~ms})$ and a later $(300 \mathrm{~ms})$ stage of stimulus processing. Moreover, to dissociate non-specific from action-specific activations, MEPs were recorded from a muscle of the right index finger (i.e., first dorsal interosseous, FDI) and from a muscle of the forearm (extensor carpi radialis, ECR), as these muscles are differently involved in generating pointillist- or brushstroke-like paintings using a precision or a power grip to hold the paintbrush (see 3.5. Control Experiment). We hypothesized that an early non-specific CSE modulation would reflect the emotional processing of artwork, supporting the emotional reactivity hypothesis (Cela-Conde et al., 2009; Kawabata \& Zeki, 2004), whilst a late muscle-specific CSE modulation would reflect motor simulation processes, supporting the embodied aesthetic hypothesis (Freedberg \& Gallese, 2007). Moreover, according to the emotional reaction hypothesis (Cela-Conde et al., 2009; Kawabata \& Zeki, 2004), we expected that the early response should occur independently of the recorded muscle and painting style. Conversely, according to the embodied aesthetic account (Freedberg \& Gallese, 2007), an action-specific modulation was expected to occur at a later processing stage in the observer's motor cortex. On the one hand, pointillist-style canvases should elicit greater CSE facilitation of the FDI, which is more involved in performing stippling movements with a precision grip. On the other hand, brushstrokestyle canvases should evoke greater CSE facilitation of the ECR, which is more involved in painting brushstrokes with a power grip. Furthermore, since previous studies have reported an influence of empathy on art appreciation (Ardizzi et al., 2020), we also collected individual measures of empathic dispositions and tested the modulatory role of perspective taking abilities on both motor facilitation and pleasantness rating responses.

\section{Material and methods}

\subsection{Participants}

Twenty-eight University students $(11$ men, aged $=24.91 \pm 6.78$ years) took part in the experiment. We determined, considering possible drop-outs, the required sample size for our $3 \times 2 \times 2$ within-subjects design (stimulus $\times$ muscle $\times$ ISI; numerator $\mathrm{df}=2$ ) through the $\mathrm{G}^{*}$ power software (Faul, Erdfelder, Lang, \& Buchner, 2007) with the "as in SPSS" option by setting the expected effect size at $\mathrm{f}(\mathrm{U})=0.457$, the significance level at 0.05 , and the desired power (1- $\beta$ ) at 0.80 . The expected effect size was estimated based on previous studies, linking aesthetic preference for paintings and motor activity (partial etasquared, $\eta^{2}=0.173$; Ticini, Rachman, Pelletier, \& Dubal, 2014).

Four participants were excluded from further analyses due to technical problems during electromyography (EMG) signal acquisition. Thus, data analyses were carried out on a final sample of 24 participants (11 males, aged $=24.92 \pm 6.79$ years). After providing an overview of the study procedure, including technical information about spTMS, all participants, who remained naïve to the specific experimental hypothesis throughout the whole experimental session, gave written informed consent. After completing the whole testing session, including also the administration of a dispositional empathy questionnaire (see below), participants were debriefed about the experimental hypothesis and they were remunerated for their participation $(£ 10 / \mathrm{h})$. All experimental procedures were in keeping with the ethical guidelines outlined by the 1964 Declaration of Helsinki as revised in 2008. The study was approved by the ethics committee of the School of Psychology of Bangor University, Bangor, UK (Application N. 2015-15,591). All participants had normal or corrected-to-normal vision and they were right-handed, as assessed by a standard Handedness Questionnaire (Oldfield, 1971). None of the participants had contraindications to TMS (Rossi, Hallett, Rossini, \& Pascual-Leone, 2009) or complained of any discomfort or adverse effect during the whole procedure.

\subsection{Stimuli}

The experimental stimuli consisted of a sample of 120 high quality color images adapted from the previous study that tested the effects of motor priming on aesthetic appreciation of canvases (Ticini, Rachman, Pelletier, \& Dubal, 2014). The sample included i) 40 pictures depicting canvases with a pointillist style, ii) 40 pictures depicting canvases with a brushstroke style, and iii) 40 photographs of historical gardens. The rationale for choosing these stimuli was that: i) pointillist-style canvases should elicit greater CSE modulation for muscles involved in performing stippling movements with a precision grip (i.e., FDI); ii) brushstrokestyle canvases should evoke greater CSE modulation for muscles involved in painting brushstrokes with a power grip (i.e., ECR). Differently, iii) garden photographs were not expected to induce a musclespecific CSE modulation in naïve viewers as they did not evoke the representation of any painting movement. Thus, photographs of gardens were used as control stimuli, providing a baseline measure. Canvas stimuli were selected not to depict human body figures or body parts in order to avoid eventual effects on CSE due to the simulation of the subject depicted in canvases (see list in Table 1). Garden photographs were taken from the web and selected to reflect different landscape garden styles and included pictures of the Château de Villandry, Chateau de Vaux-le-Vicomte, Gardens of Versailles, and Parc de Sceaux in France, of the Padua Botanic Garden, Royal Palace of Caserta, Villa Lante, and Villa Parco Bolasco in Italy; of the Belvedere Museum Vienna in Austria; and of the Stowe Gardens in England. Examples of stimuli are shown in Fig. 1. All images were adjusted to a frame size of $470 \times 351$ pixels using Adobe Photoshop (Adobe Inc., San Jose, CA) and were presented on a screen with a resolution of $1280 \times 800$ pixels at a $55-\mathrm{cm}$ distance to subtend $12^{\circ}$ horizontal and $9^{\circ}$ vertical visual angles.

\subsection{EMG and TMS}

EMG was recorded with silver disc surface electrodes positioned on the FDI and ECR muscles in a belly-tendon configuration. Electrode position for the FDI and the ECR muscles was determined by palpation during maximum voluntary muscles activation (i.e., the abduction of the index finger toward the thumb while the experimenter exerted a pressure against the radial side of the index finger in the direction of the middle finger for the FDI muscle; the extension of the wrist toward the radial side while the experimenter exerted a pressure against the dorsum of the hand for the ECR muscle). After skin cleaning, electrodes containing a small amount of water-soluble conductive paste were placed and fixed on each target positions. The reference electrodes were placed over the ipsilateral metacarpal phalangeal joint for the FDI muscle and on the ulnar styloid process for the ECR. The ground electrode was placed at the right elbow. Electrodes were connected to a Biopac MP-36 system (BIOPAC Systems, Inc., Goleta, CA) allowing amplification, band-pass filtering ( $5 \mathrm{~Hz}$ to $20 \mathrm{kHz}$, notch filter $50 \mathrm{~Hz}$ ) and digitization 
Table 1

List of the pointillist- or brushstroke-style paintings used as experimental stimuli.

\begin{tabular}{|c|c|}
\hline Pointillist & Brushstroke \\
\hline Cross, Henri-Edmond (1891). The Golden Isles & Alexander, David (2012). Reed Bottom Lines \\
\hline Cross, Henri-Edmond (1906). Undergrowth & Alexander, David (2012). See Throughs \\
\hline Cross, Henri-Edmond (). Cypresses at Cagnes & Arnold, Kathryn (2010). Leveling the Clouds \\
\hline Dellavallée, Henri (1887). La Rue au Soleil à Port-Manech & Arnold, Kathryn (2010). Silk Wind \\
\hline Dellavallée, Henri (1887). Farmyard & Benini, Alessandra (2001). La maison d'artiste \\
\hline Dubois, Louis (1888). La Marne à l'Aube & Cezanne, Paul (1904). Mont Sainte-Victoire \\
\hline Franco, Angelo (2007). Blooming Tree & Cezanne, Paul (1906). Bend in forest road \\
\hline Franco, Angelo (2010). Abstract Forest IV & Cezanne, Paul (1905). Riverbanks \\
\hline Franco, Angelo (2011). Forest Abstraction & Huys, Modest (1919). Ruins of Elverdinge \\
\hline Franco, Angelo (2011). Forest Abstraction \#6 & Lemmen, Georges (1891). Heyst No.9 The Beach \\
\hline Franco, Angelo (2011). Forest of Love & Monet, Claude (1881). Wheat Field \\
\hline Franco, Angelo (2011). Virginia Forest Abstraction 1 & Monet, Claude (1882). Shadows on the Sea - the Cliffs at Pourville \\
\hline Franco, Angelo (2012). Portrait of a Hill & Monet, Claude (1885). The Cliff Of Aval Etretat \\
\hline Franco, Angelo (2012). Rare Bird & Purrmann, Hans (1909). Coastal landscape near Cassis \\
\hline Holton, William (2005). Fallout & Signac, Paul (1885). Saint Briac, Courtyard of the Ville Hue \\
\hline Lacombe, Georges (1909). In the Forest & Signac, Paul (1895). Saint Tropez the Gust of Eastern Wind \\
\hline Lemmen, Georges (1891). Beach at Heist & van Gogh, Vincent (1887). Wheat Field with a Lark \\
\hline Lemmen, Georges (1892). View of the Thames & van Gogh, Vincent (1888). Public Park with Weeping Willow \\
\hline Lemmen, Georges (1894). Factories on the Thames & van Gogh, Vincent (1889). Cypresses \\
\hline Luce, Maximilien (1890). The Seine at Herblay & van Gogh, Vincent (1889). Olive Grove \\
\hline Luce, Maximilien (1900). Montmartre - de la Rue Cortot, Vue vers Saint-Denis & van Gogh, Vincent (1889). Olive Orchards - Bright Blue Sky \\
\hline Malevich, Kazimir (1908). Landscape & van Gogh, Vincent (1889). Starry Night \\
\hline Matisse, Henri (1904). Le Cap Layet & van Gogh, Vincent (1890). Doctor Gachet's Garden \\
\hline Metzinger, Jean (1905). Le Château de Clisson & van Gogh, Vincent (1890). Landscape near Auvers - Wheatfields \\
\hline Metzinger, Jean (1905). Paysage au Deux Cypres & van Gogh, Vincent (1890). Old Farmhouses in Auvers \\
\hline Metzinger, Jean (1905). Paysage Neo-Impressiste & van Gogh, Vincent (1890). Road with Cypres and a Star \\
\hline Metzinger, Jean (1906). Matin au Parc Montsouris & Van Gogh, Vincent (1889). The Olive Trees \\
\hline Metzinger, Jean (1906). Parc Monceau & van Gogh, Vincent (1889). Wheat Field With Cypresses \\
\hline Picabia, Francis (1909). View of St. Tropez from the Citadel & van Gogh, Vincent (1890). Houses at Auvers \\
\hline Seurat, Georges (1888). Port-en-Bessin - Avant-Port Marée Haute & van Gogh, Vincent (1890). Wheatfield with Crows \\
\hline Seurat, Georges (1888). Port-en-Bessin - Entrance to the Harbor & van Gogh, Vincent (1888). Orchard in Blossom (Plum Trees) \\
\hline Seurat, Georges (1890). Gravelines Annonciade & van Gogh, Vincent (1889). Green Wheat Field with Cypress \\
\hline Signac, Paul (1889). River's Edge - the Seine at Herblay & van Gogh, Vincent (1889). Evening Landscape with Rising Moon \\
\hline Signac, Paul (1900). Palais des Papes Avignon & van Gogh, Vincent (1889). Wheatfield with Rising Sun \\
\hline Signac, Paul (1909). Pine Tree at Saint-Tropez & van Gogh, Vincent (1888). Path Through a Field with Willows \\
\hline Signac, Paul (1915). Le Port de la Rochelle & van Gogh, Vincent (1890). Field with Stacks of Wheat \\
\hline Signac, Paul (1897). View of Saint-Tropez & van Gogh, Vincent (1890). Green Wheat Fields, Auvers \\
\hline Sokolov, Anatoly (2008). Abstraction Painting 002 & van Gogh, Vincent (1889). Les Peiroulets Ravine \\
\hline van Rysselberghe, Théo (1892). Sailboats and Estuary & van Gogh, Vincent (1890). Wheat Field at Auvers with White House \\
\hline van Rysselberghe, Théo (1896). Pointe Saint-Pierre at Saint-Tropez & van Gogh, Vincent (1888). Wheat Fields near Auvers \\
\hline
\end{tabular}

of the EMG signal (sampling rate: $50 \mathrm{kHz}$ ). The signal was stored on a personal computer for display and later off-line data analyses.

TMS was delivered to the scalp portion overlying the left motor hand region through a 50-mm-figure-of-eight coil (Magstim polyurethanecoated coil) connected to a Magstim 2 stimulator (Magstim Company, Carmarthenshire, Wales, UK). We determined the optimal position for activation of both muscles (i.e. the scalp position from which maximal amplitude MEPs were elicited) by moving the coil in approximately 0.5 $\mathrm{cm}$ steps around the presumed motor hand area and stimulating with a constant, slightly supra-threshold stimulus intensity. The coil was placed tangentially to the scalp with the handle pointing backward and laterally to form a $45^{\circ}$ angle with the sagittal plane. This coil orientation induced a posterior-anterior current in the brain. The optimal position of the coil was then marked with a pen on a cap placed on the scalp to ensure correct coil placement throughout the experiment. For the whole experiment, the coil was fastened to an articulated mechanical arm. The resting motor threshold (rMT) was then defined as the minimum stimulus intensity (expressed as percentage of maximum stimulator output) able to produce MEPs of at least $0.05 \mathrm{mV}$ peak-to-peak amplitude in at least 5 out of 10 consecutive trials (Rossini et al., 2015) in the lower threshold muscle (i.e., FDI). This procedure was used to avoid saturation of its CSE modulation (Devanne, Lavoie, \& Capaday, 1997) and possible loss of observation-related modulation (Loporto, Holmes, Wright, \& McAllister, 2013). Participants' rMT ranged from 33\% and 75\% (mean $\mathrm{rMT}=44.42 \pm 10.42 \%$ ) of the maximum stimulator output. During the experiment, spTMS was applied over the identified hotspot at a stimulation intensity corresponding to $120 \%$ of the individual's rMT. This procedure allowed us to reliably record MEPs from both muscles. The EMG data were collected for $250 \mathrm{~ms}$ starting at $100 \mathrm{~ms}$ before the TMS pulse.

\subsection{Task and procedure}

\subsubsection{Art familiarity}

Before starting the main experimental sessions, we assessed participants' familiarity with art through the Art Experience Questionnaire (Chatterjee, Widick, Sternschein, Smith, \& Bromberger, 2010), adapted to the European context (Ticini, Rachman, Pelletier, \& Dubal, 2014). This self-report screening questionnaire consists of 8 items ascertaining experience in studio art, art history, theory and aesthetics classes taken at high school level or above, the frequency in visiting museums or galleries, and the approximate number of hours spent each week in making art, reading artistic publications, or looking at art. For the purpose of the current study, this questionnaire allowed probing that participants were artistically-naïve subjects.

\subsubsection{Experimental sessions}

The main experiment consisted of three consecutive experimental sessions, performed in the same day and overall lasting approximately $60 \mathrm{~min}$.

In an initial visuomotor training session, participants were motorically primed to two different painting styles by being asked to paint on 

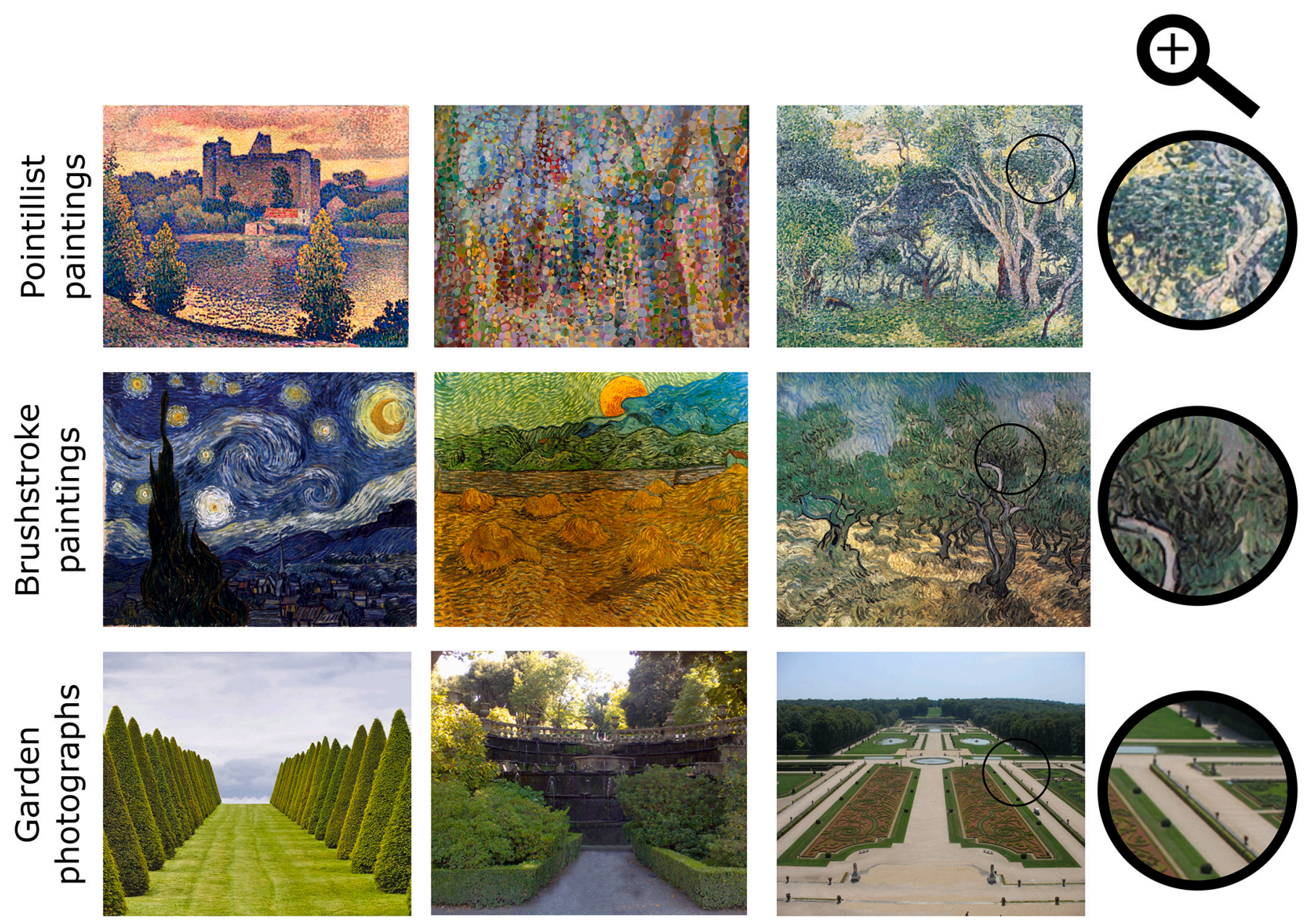

Fig. 1. Examples of pointillist and brushstroke paintings and of garden photographs.

For pointillist paintings, from the left: "Le Château de Clisson" (Metzinger, Jean, 1905); "Forest Abstraction \#6" (Franco, Angelo, 2011); "Undergrowth" (Cross, HenriEdmond, 1906). For the brushstroke paintings, from the left: "Starry Night" (van Gogh, Vincent, 1889); "Evening Landscape with Rising Moon" (van Gogh, Vincent, 1889); "The Olive Trees" (Van Gogh, Vincent, 1889). For the garden photographs, from the left: Photographs from the Gardens of Versailles; the Padua Botanic Garden, the Chateau de Vaux-le-Vicomte.

white sheets of paper with a pointillist- (on 10 sheets of paper) or brushstroke-like (on another 10 sheets of paper) style (Fig. 2A). They were free to choose the order between the two styles and the objects of their painting, but they were instructed to grab the paintbrush by using a precision grip for the pointillist-style and a power grasp for the brushstroke-style paintings. This procedure allowed participants to familiarize themselves with the two styles while strengthening the association between the style and the movement to perform it (Ticini, Rachman, Pelletier, \& Dubal, 2014). During this visuomotor training, EMG activity was not recorded. In keeping with previous studies (Ticini et al., 2014), the rationale for performing this training was to prime participants with a specific association between different painting styles and different ways to grasp and hold the brush to paint. In particular, we tried to ensure that all participants associated a precision grip of the brush with the movements performed to produce a pointillist-like painting and between a power grip of the brush and the movements performed to produce a brush-stroke-like painting. This way, we aimed to reduce interindividual variability in the motor strategies for holding the brush to produce pointillist- or brushstroke-like paintings, which could be particularly relevant in our sample of art-naïve participants.

During the TMS session, participants were seated on a comfortable chair with their right forearm resting on a pillow. They were instructed to keep their hands still and as relaxed as possible. They were asked to perform a liking rating task: they were presented with the pictures of canvases or garden photographs and in each trial, after stimulus offset, they were asked to rate on a 7-point Likert like scale how much they liked the target image. Thus, participants were involved in an explicit aesthetic task, being in an aesthetic evaluation mode during CSE assessment. Two repetitions for each stimulus with the early or the late TMS delay were presented, thus leading to a total of 240 trials (i.e., 40 trials per cell). All trials were presented and randomized in four blocks of 60 trials. Furthermore, in two baseline blocks administered before and after the liking-rating task, MEPs were recorded while participants observed a fixation cross (20 trials per block).

Each trial started with the presentation of a central fixation cross, lasting $500 \mathrm{~ms}$, and it was followed by the presentation of the experimental pictures (lasting $350 \mathrm{~ms}$ ). Crucially, the spTMS was delivered at either $150 \mathrm{~ms}$ (early TMS delay) or $300 \mathrm{~ms}$ (late TMS delay) after the onset of the target picture (Fig. 2B). At picture offset, a response frame with the task question (How much do you like it?), the verbal descriptors (Not at all - Very Much) and the 7 numbers of the Likert scale written in white on a black background were presented. Importantly, we counterbalanced across trials the left- or right-position of the Likert verbal descriptors and numbers to prevent possible effects of motor preparation or of spatial attention on CSE. Participants were required to verbally indicate their response, which was recorded by the experimenter using a computer keyboard. A verbal, rather than a motor, response was requested to avoid MEP contamination (Gentilucci, Bernardis, Crisi, \& 
a)

Visuomotor training

$10 x$
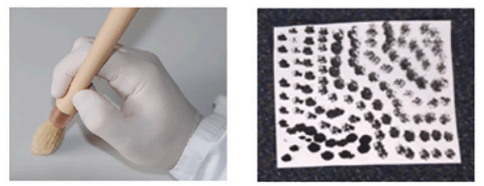

$10 x$
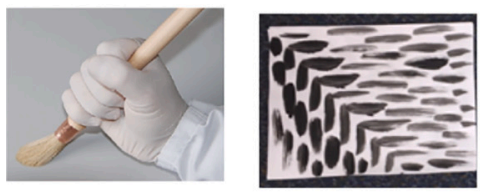

TMS session

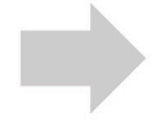

Questionnaire session
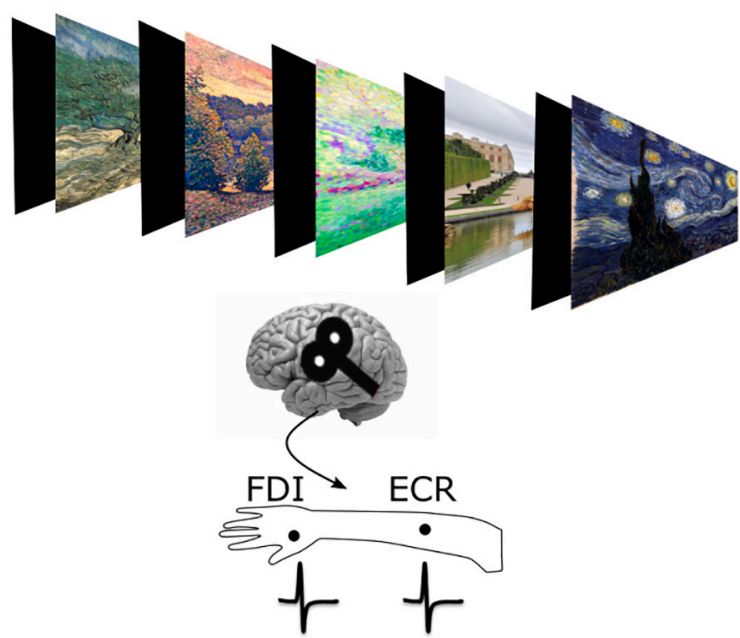

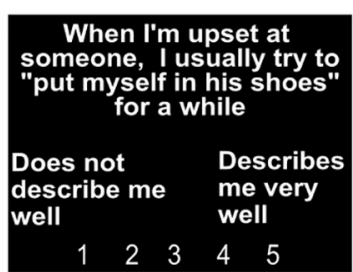

\section{b)}

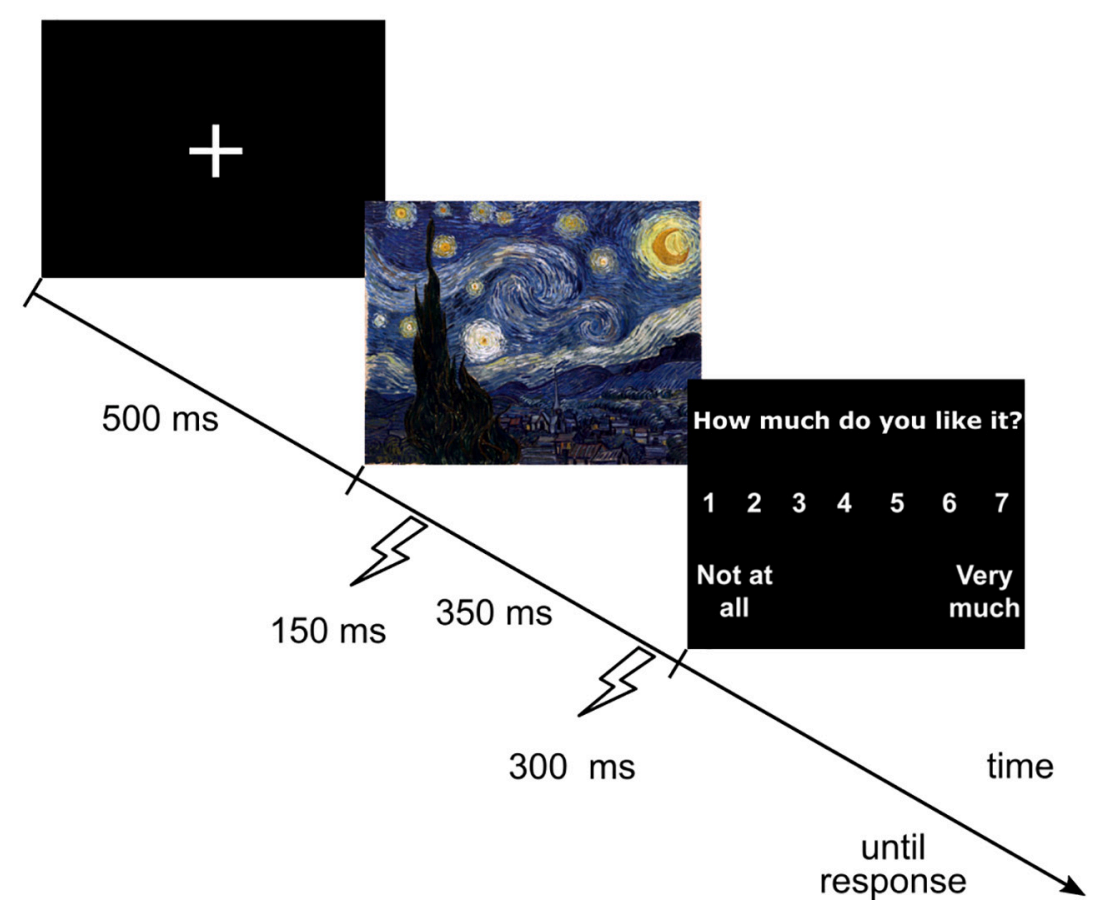

Fig. 2. Schematic representation of the experimental sessions in the main experiment (a) and of the trial procedure in the TMS session (b).

a) The main experiment comprised three consecutive sessions: i) a visuomotor training, ii) a transcranial magnetic stimulation (TMS) session and iii) a questionnaire session. In the visuomotor training session, participants were required to produce 10 pointillist-like paintings using a precision grip to grasp the brush (upper figures) and ten brushstroke-like paintings using a power grip (lower figures). Soon after the visuomotor training, the same participants were involved in the TMS session. During this session, single-pulse TMS was delivered at each trial and Motor Evoked Potentials (MEPs) were recorded from the right first dorsal interosseous (FDI) and extensor carpi radialis (ECR) muscles after presentation of a pointillist or brushstroke painting or of a garden photograph. In each trial, participants were asked to express their liking of the observed picture. At the end of the TMS session, the participants filled out the Interpersonal Reactivity Index questionnaire. b) The figure depicts an example of a pointillist painting trial. For each trial, the presentation of the fixation cross was followed by the presentation of the target stimulus for 350 ms. Within this time window, the TMS pulse was delivered at an early (after $150 \mathrm{~ms}$ ) or a late (after $300 \mathrm{~ms}$ ) delay after the onset of the picture and MEPs were recorded. The target stimulus was followed by the presentation of a response frame with the liking 7-point Likert scale, which remained on the screen until participant's verbal response. 
Dalla Volta, 2006; Tokimura, Tokimura, Oliviero, Asakura, \& Rothwell, 1996). No time limit was given for the response, but participants were invited to respond as soon as possible. A black screen was presented in the inter-trial interval (lasting $5000 \mathrm{~ms}$ ). This way, the inter-pulse interval was longer than $10 \mathrm{~s}$, thereby avoiding changes in CSE due to repeated exposure to TMS pulses (Chen et al., 1997).

After the completion of the TMS session, we measured participants' dispositional empathy by means of a computerized version of the Interpersonal Reactivity Index (IRI; (Davis, 1996)). This questionnaire consists of 28 self-report items, and it measures empathy-related dispositions by means of four subscales, namely: Perspective Taking (PT), which assesses the tendency to assume the cognitive perspective of another person; Fantasy Scale, which assesses the tendency to imaginatively transpose oneself into fictional characters' feelings and actions; Empathic Concern, which assesses "other-oriented" feeling of sympathy and concern for others in need; and Personal Distress, which measures self-oriented feelings of personal anxiety and distress when facing others' emotional unease. Importantly, while the PT and the Fantasy Scale subscales tap into cognitive empathy, the Empathic Concern and the Personal Distress subscales are more related to emotional reactivity. In particular, cognitive traits and especially PT have been shown to be associated with motor activation during aesthetic experience (Ardizzi et al., 2020).

\subsection{Control experiment}

Muscle specificity of CSE modulation during action observation is considered as a hallmark of action simulation as action observation is expected to facilitate CSE only in the muscles that are used during the execution of the same movements (Amoruso \& Finisguerra, 2019; Naish, Houston-Price, Bremner, \& Holmes, 2014; Urgesi et al., 2006). Indeed, a muscle-specific CSE modulation during action observation implies a change in the activation of the cortico-spinal representation of the muscles that are specifically involved in either action execution or observation (Fadiga et al., 2005). Thus, to ensure that any musclespecific modulation of CSE during the observation of pointillist- or brushstroke-style paintings reflect action simulation, we needed to assess the specific involvement of the recorded muscles while performing pointillist- or brushstroke-like movements.

To this aim, we recorded the EMG activity of the FDI and ECR muscles during the execution of movements associated with a pointillistlike or a brushstroke-like style in a separate control experiment. Accordingly, EMG recordings of four additional right-handed participants ( 1 male, age $=32 \pm 4.34$ years) who were not involved in the main experiment were collected. In each trial, as during the visuomotor training preceding the TMS experiment, participants were asked to paint either pointillist-like or brushstroke-like drawings by holding a paintbrush with their right hand with a precision grip or a power grip, respectively. Participants were asked to perform the movements in a natural way according to verbal instructions that informed them about the style to follow. Crucially, here we recorded EMG activity from the FDI and ECR muscles while the participants were producing their drawings. Thus, the participants were required to perform the movement only after the presentation of an auditory go signal. The EMG recording in each trial started $200 \mathrm{~ms}$ before the go signal and lasted for $2000 \mathrm{~ms}$. During this control experiment, participants performed 20 pointillist-like and 20 brushstroke-like movements, leading to a total of 40 trials. Before starting the EMG recording, participants were briefly trained how to perform the movements.

\subsection{Data analysis}

All analyses were performed using repeated-measures Analysis of Variance (RM-ANOVA) designs implemented in the STATISTICA software (Stat Soft, version 10, StatSoft Inc., Tulsa, OK). Estimates of the effect size were obtained using $\eta_{p}^{2}$ for ANOVA effects and Cohen's $d$ for $t$ - tests. Post-hoc analysis was performed using the Duncan's test correction, which was developed to reduce the risk of false negative (Type II) error when correcting for multiple comparisons (Editor IJSMI, 2016). In particular, the Duncan test is a sequential post-hoc test that reduces the size of the critical difference depending on the number of steps separating the ordered means; this procedure is optimal for testing in the same design effects that may have different sizes (Duncan, 1955; Dunnett, 1970; McHugh, 2011). The significance threshold was set at $p=.05$ for all statistical tests.

\subsubsection{Art familiarity}

To test whether our participants were truly artistically-naïve, the total average of the summed score for each question obtained in the Art Experience Questionnaire was compared with the corresponding total score obtained in a group of naïve participants $(N=18$; Ticini, Rachman, Pelletier, \& Dubal, 2014) by means of two-tailed, independentsample $t$-test.

\subsubsection{MEP data}

An epoch of $100 \mathrm{~ms}$ of EMG activity was recorded before each TMS pulse to ensure MEPs were recorded during full muscle relaxation. Separately for each muscle, trials with background EMG activity exceeding the mean background activation for at least 2 SD (i.e., precontraction trials) and trials with MEP amplitude that was 2 SD below the mean background activity (i.e., trials with MEPs not distinguishable from noise) were removed from the analysis. For all the remaining trials $(89.9 \%, S D=11.0 \%$ for the FDI muscle, and $86.7 \%, S D=13.8 \%$ for the ECR), we extracted the peak-to-peak amplitude (expressed in $\mathrm{mV}$ ) of MEPs recorded from the FDI and ECR muscles during: i) the fixationcross observation trials in the two baseline blocks (Pre, Post), and during the observation of ii) pointillist-style painting, iii) brushstroke-style paintings and iv) garden photographs across the four experimental blocks. MEP amplitudes were then averaged for each experimental condition, separately for each participant and for the two muscles, and used for further analyses. To reduce the positive skewness resulting from preliminary descriptive analyses (skewness z scores $>1.96, p<.05$ for all variables), we applied a logarithmic transformation with $\log 10$ and constant value of 1 (Osborne, 2003) on the mean MEP amplitudes for each variable. Then, for each muscle, we first compared MEPs recorded during the two baseline sessions (Pre, Post) by means of a two-tailed dependent-sample t-test. Once we verified that no significant changes in CSE occurred for the two muscles between the beginning and the end of the experiment, we proceeded with the following analyses. To obtain a measure of motor facilitation that was specific for the observed painting style but independent from the contingent effect due to the observation of complex (colored) and pleasant scenes, we calculated normalized indices of CSE modulation for the pointillist-style and the brushstroke-style paintings, separately for the two muscles. These indices corresponded to the percentage difference between the individual mean MEP amplitude during the observation of pointillist-style or brushstroke-style paintings and the individual mean MEP amplitude during the observation of garden photographs. The indices were entered into a $2 \times 2 \times 2$ RM-ANOVA with style (pointillist, brushstroke), TMS delay (early, late) and muscle (FDI and ECR) as within-subjects variables.

\subsubsection{Likert liking ratings}

Liking scores for pointillist and brushstroke canvases and for garden photographs were averaged for each participant. To assess the presence of a preference for one the three stimulus categories, individual liking ratings for each stimulus type were entered into a one-way three-level RM-ANOVA.

\subsubsection{Correlation analyses}

We explored the relationship between CSE modulation to the observation of pointillist- and brushstroke-style paintings and the 
subjective liking measures. Specifically, in keeping with MEP data handling, we calculated, separately for the two TMS delays, the percentage difference between the individual mean Likert scores for the pointillist- or the brushstroke-style paintings and those for garden photographs. Then, we computed the Pearson correlation coefficients between the indices of CSE modulation activation and the indices of liking ratings modulation for the corresponding painting style and spTMS delay. Furthermore, we computed the Pearson correlation coefficients between the modulation indices of CSE and of liking ratings for the pointillist- and the brushstroke-style paintings and the individual scores at the PT subscale of the IRI questionnaire, in order to test the relationship between motor and subjective responses to paintings and cognitive empathy.

Based on the correlation patterns, we used mediation analysis following established methods (MacKinnon, Warsi, \& Dwyer, 1995) to understand whether the influence of an independent variable (IV) on a dependent variable (DV) could be accounted for or not by a mediator (M). Mediation effects were tested using the Sobel test, by applying the Goodman correction (Goodman, 1960; MacKinnon et al., 1995). Onetailed effects were tested since the direction of the mediation was predicted on the basis of the correlation analysis.

\subsubsection{Control experiment}

EMG data were processed offline. For each trial, the signal was rectified and averaged into bins of $200 \mathrm{~ms}$. The mean rectified EMG signal (in $\mathrm{mV}$ ) in each bin was measured starting from $200 \mathrm{~ms}$ before the go signal up to $1800 \mathrm{~ms}$ after it (for a total of 10 bins). For each trial, the mean EMG signal of the first artifact-free bin was used as baseline. To allow comparison between style-conditions and participants, the EMG signal for each trial was expressed as a percentage of its baseline value (EMG ratio values). We removed from the analysis $8.43 \%$ of the trials due to failure in data acquisition or because they were highlighted as outliers for at least three consecutive bins. Then, we aligned the bins of all trials for each participant, muscle and painting condition according to the bin with maximal mean activation (activation peak). The mean activation values of the 5 bins (i.e., $1000 \mathrm{~ms}$ ) around the activation peak of each trial were entered into two separate linear mixed models implemented in SPSS, one for each muscle, with painting style (two levels: pointillist and brushstroke styles), and bins (five levels) as fixed factors, and subject (four levels) as a random factor. To explore the temporal profile of muscular activations, significant effects were explored by means of trend analysis, investigating whether the temporal deployment of EMG activation for each condition across bins was best fitted by a linear, quadratic or cubic trend. Pairwise comparisons were also performed to test for significant differences between conditions.

\section{Results}

\subsection{Art familiarity}

Independent-sample $t$-test comparisons between the total score obtained in our sample $(8.5 \pm 6.1)$ for the Art familiarity questionnaire and the corresponding total score in Ticini, Rachman, Pelletier, \& Dubal, 2014 's sample of art-naïve participants $(6.61 \pm 4.85)$ showed nonsignificant differences between the two groups $(\mathrm{t}(40)=1.08 ; p=$ $.286, d=0.34$ ), confirming that our participants were artistically-naïve participants.

\subsection{MEP data}

MEP values recorded during the baseline sessions at the beginning and at the end of the experimental session did not significantly differ for either muscle (FDI: $\mathrm{t}(23)=-1.91, p=.07, \mathrm{~d}=0.56$ ); ECR: $\mathrm{t}(23)=$ $-0.71, p=.49, \mathrm{~d}=0.21$ ), showing that baseline CSE did not significantly change in the experiment. The raw MEP amplitudes recorded in the three observation conditions are reported in Table 2. The 3-way style
Table 2

Mean ( \pm standard error) raw amplitude (in mV) of Motor Evoked Potentials (MEPs) recorded from the two muscles at the early and late stimulation delays and of the liking Likert ratings provided during the observation of the three stimulus types.

\begin{tabular}{|c|c|c|c|c|c|}
\hline & FDI & FDI & ECR & ECR & $\begin{array}{l}\text { Liking } \\
\text { ratings }\end{array}$ \\
\hline & $\begin{array}{l}\text { Early } \\
\text { delay }\end{array}$ & Late delay & $\begin{array}{l}\text { Early } \\
\text { delay }\end{array}$ & Late delay & \\
\hline Pointillist & $\begin{array}{l}1.07 \pm \\
0.19\end{array}$ & $\begin{array}{l}1.10 \pm \\
0.21\end{array}$ & $\begin{array}{l}0.53 \pm \\
0.09\end{array}$ & $\begin{array}{l}0.51 \pm \\
0.09\end{array}$ & $4.05 \pm 0.24$ \\
\hline Brushstroke & $\begin{array}{l}1.06 \pm \\
0.18\end{array}$ & $\begin{array}{l}1.08 \pm \\
0.19\end{array}$ & $\begin{array}{l}0.51 \pm \\
0.08\end{array}$ & $\begin{array}{l}0.52 \pm \\
0.08\end{array}$ & $3.98 \pm 0.22$ \\
\hline Garden & $\begin{array}{l}1.08 \pm \\
0.18\end{array}$ & $\begin{array}{l}1.08 \pm \\
0.19\end{array}$ & $\begin{array}{l}0.54 \pm \\
0.09\end{array}$ & $\begin{array}{l}0.50 \pm \\
0.08\end{array}$ & $4.28 \pm 0.26$ \\
\hline
\end{tabular}

$\times$ delay $\times$ muscle RM-ANOVA performed on the normalized indices of CSE modulation during observation of brushstroke- and pointillist-style paintings (vs. gardens photographs) revealed a significant 2-way style $\times$ delay interaction $\left(\mathrm{F}(1,23)=4.91, p=.037, \eta_{\mathrm{p}}^{2}=0.18\right)$, which was further qualified by the significant 3-way interaction with muscle ( $F$ $\left.(1,23)=4.35, p=.048, \eta_{p}^{2}=0.16\right)$. This interaction was explored by testing, separately for the two muscles, the 2-way style $\times$ delay RMANOVA model. Concerning the analysis performed on MEPs recorded from the FDI muscle, no main effects or interaction were significant (all $\mathrm{F}<1.57$; all $p>.22$ ). Conversely, the analysis performed on the ECR MEPs revealed a significant style $\times$ delay interaction $(\mathrm{F}(1,23)=9.66, p$ $=.005, \eta_{\mathrm{p}}^{2}=0.30$, Fig. 3). Post-hoc analyses showed that the ECR modulation during the observation of pointillist-style paintings was not significantly different between the early and late spTMS delays (early: $1.59 \pm 3.07 \%$; late: $-2.18 \pm 2.63 \% ; p=.10$ ). Conversely, during the observation of brushstroke-style paintings, the ECR CSE significantly increased when TMS pulse was delivered at the late $(3.44 \pm 2.14 \%)$ with respect to early delay $(-2.39 \pm 2.39 \% ; p=.021)$. Importantly, the ECR CSE at the late spTMS delay was significantly higher during observation of brushstroke-style paintings than during observation of pointillist-style paintings $(p<.022)$. No other comparisons were significant (all $p>.09$ ). (Fig. 3; Table 2).

\subsection{Likert liking ratings}

No preferences for one of the two artwork styles nor for gardens photographs (see Table 2) was confirmed by the one-way ANOVA, in which a non-significant effect of style was found $(\mathrm{F}(2,46)=0.37, p=$ .695, $\left.\eta_{p}^{2}=0.016\right)$.

\subsection{Correlation analyses}

Based on the main CSE modulation results, we restricted the correlation analyses to the relationships between the ECR CSE modulation for brushstroke-style paintings at the late spTMS delay, the aesthetic appreciation modulation for brushstroke-style paintings at the late spTMS delay, and the dispositional empathy scores at the PT sub-scale of the IRI questionnaire. Cook's distance was used to identify influential data points leading to the exclusion of 2 participants as outliers (Cook \& Weisberg, 1983). A false discovery rate (FDR) correction was used to control for multiple correlation testing.

We found that the ECR CSE modulation at the late spTMS delay showed a significant negative correlation with the corresponding index of liking ratings for brushstroke-style paintings $\left(r=-0.46, \mathrm{p}_{\text {(corrected) }}=\right.$ 0.032; Fig. 4a) and with PT dispositions $\left(r=-0.489\right.$, $\mathrm{p}_{\text {(corrected) }}=0.032$; Fig. 4b). Interestingly, a positive correlation between the index of liking ratings for brushstroke-style paintings and PT dispositions was found ( $r$ $=0.56, \mathrm{p}_{\text {(corrected) }}=0.014$; Fig. 4c).

Given this pattern of trine reciprocal correlations, we asked whether dispositional empathy influenced both the CSE modulation and the 
a)

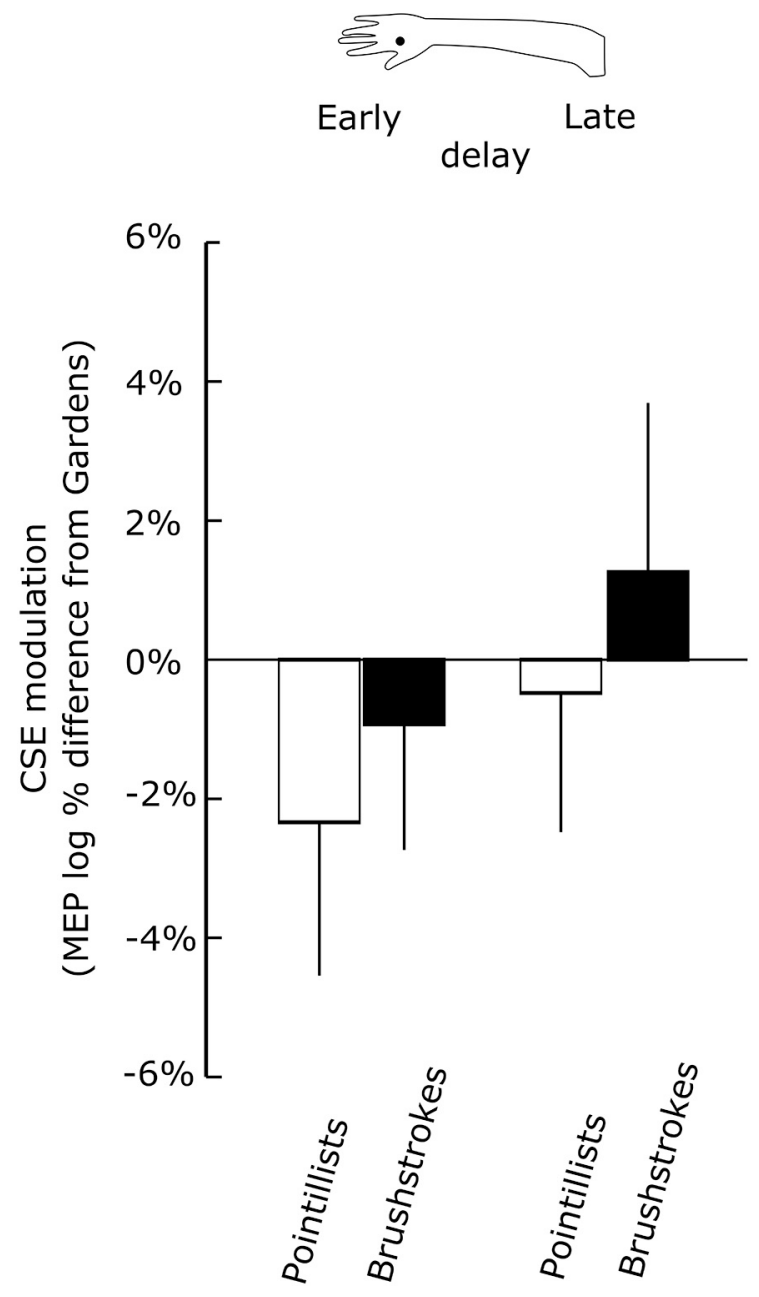

b)

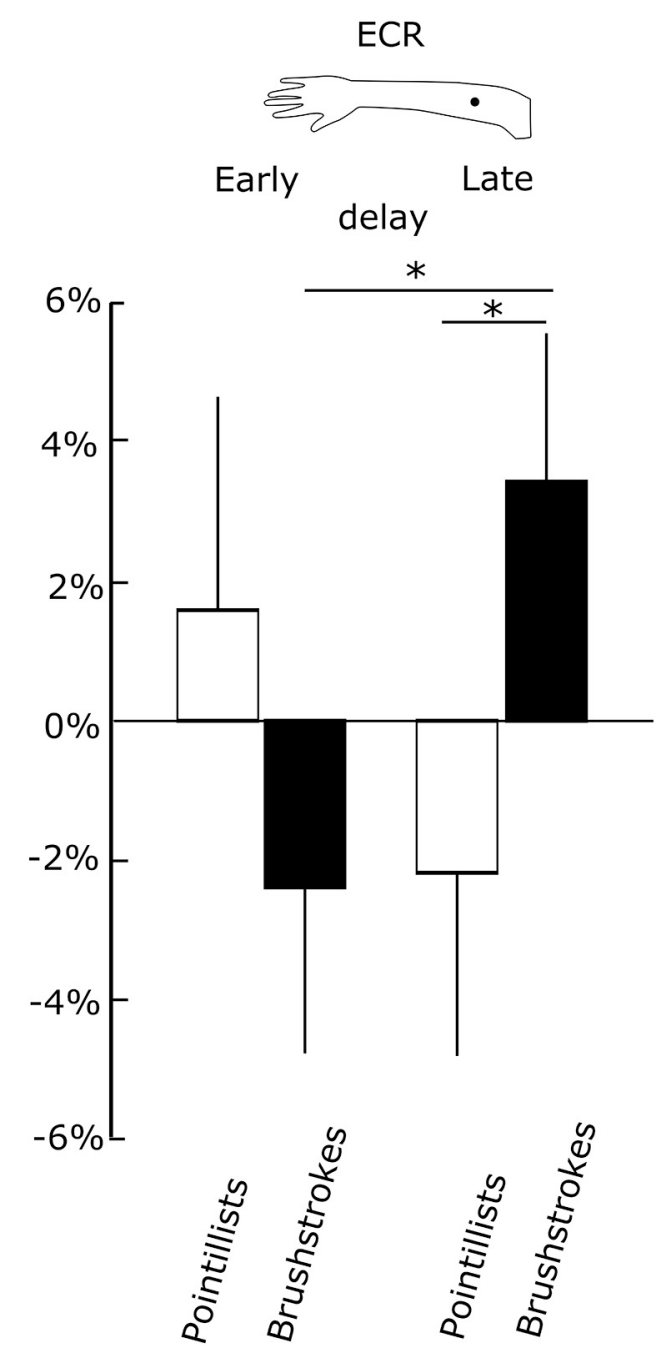

Fig. 3. Effects of painting observation on the modulation of cortico-spinal excitability (CSE).

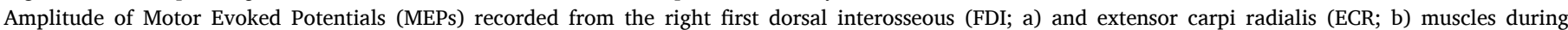

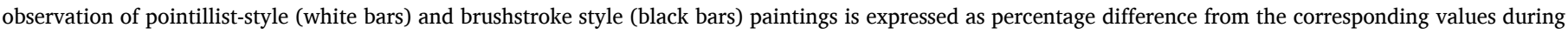

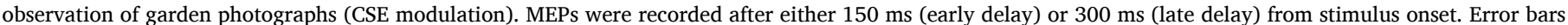
indicate standard error of the mean. Asterisks indicate significant pair-wise comparisons $(p<.05)$.

a)

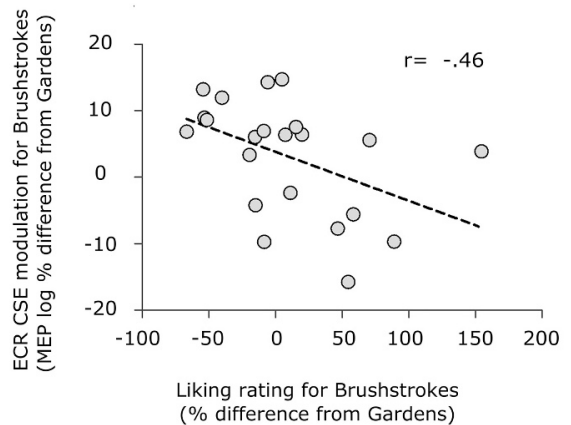

b)

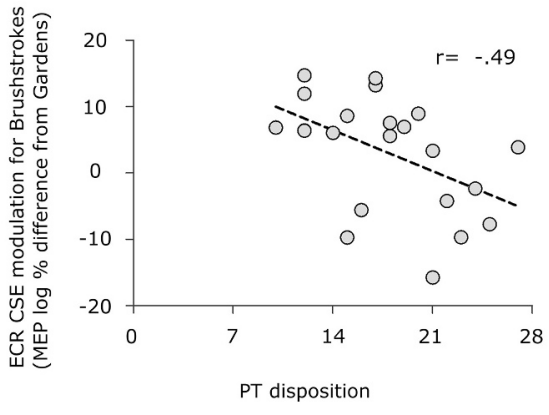

c)

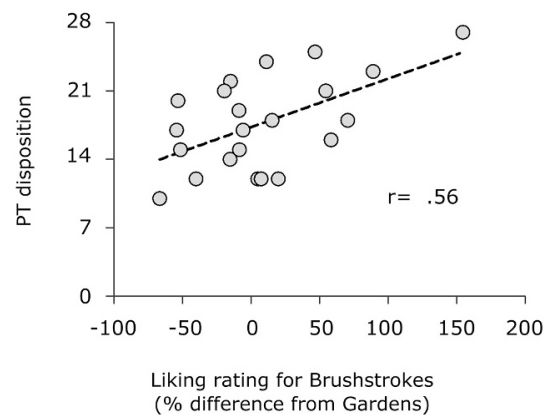

Fig. 4. Correlation between modulation of cortico-spinal excitability (CSE) and the liking judgments and empathy scores of the observers.

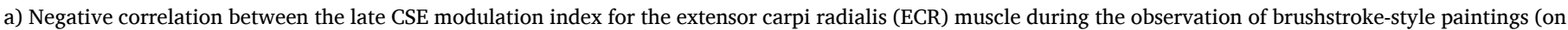

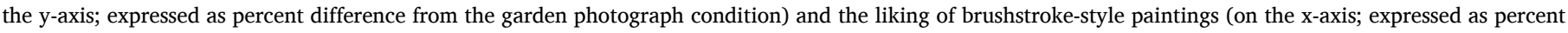

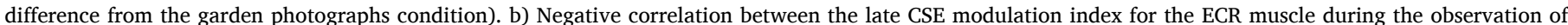

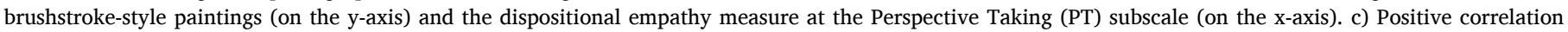

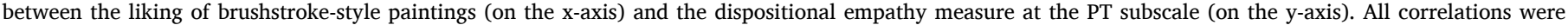
significant at $\mathrm{p}<.05$, after correction for multiple testing. 
aesthetic appreciation directly, or whether the influence of PT on one variable (i.e., CSE or aesthetic appreciation modulation) was mediated by the other variable. Analogously, we tested whether dispositional empathy mediated the relationship between aesthetic appreciation and CSE modulation. Thus, four models were tested. With respect to the first model (i.e., mediation of liking ratings on the influence of PT abilities on CSE modulation; Fig. 5a), we found that while PT negatively predicted CSE modulation, this influence was not mediated by the liking ratings (Sobel test, $\mathrm{z}=-1.14, p=.13$ ). Analogously, for the second model (i.e., mediation of CSE modulation on the influence of PT abilities on liking ratings; Fig. 5b), we found that while PT positively predicted liking ratings, no evidence of mediation by CSE modulation was found (Sobel test, $\mathrm{z}=1.13, \mathrm{p}=.13$ ). Moving to a possible role of PT abilities in mediating the relationship between CSE modulation and liking ratings, when we tested for the third model (i.e., mediation of PT abilities on the influence of liking ratings on CSE modulation; Fig. 5c), we found that the significant influence of liking ratings on CSE modulation was not mediated by PT (Sobel test, $\mathrm{z}=-1.37, p=.08$ ). Conversely, only for the fourth model (i.e., mediation of PT on the influence of CSE modulation on liking ratings; Fig. 5d) we found evidence of mediation, since the negative relationship between CSE modulation and liking ratings was significantly affected by the inclusion of dispositional empathy as a mediator (Sobel test, $\mathrm{z}=1.68 ; p=.047$ ).

\subsection{Control experiment}

The linear mixed model on the EMG ratio values recorded from the FDI muscle revealed significant main effects of the fixed factors Bin (F $(4,790)=8.87, p<.001)$ and Style $(\mathrm{F}(1,790)=49.42, \mathrm{p}<.001)$, but a non-significant interaction between Style and Bins $(\mathrm{F}(4,790)=1.47, p$ $=.209$ ). Thus, the pattern of EMG activation of the FDI muscle was overall higher for painting with a pointillist- than brushstroke-like style, but no differentiation of its motor involvement was found during the movement (Fig. 6). Conversely, the linear mixed model on values recorded from the ECR muscle revealed significant main effects of Bin (F
$(4,790)=43.7, \mathrm{p}<.001)$, Style $(\mathrm{F}(1,790)=212.59, \mathrm{p}<.001)$, and $\mathrm{a}$ significant interaction between Style and $\operatorname{Bin}(\mathrm{F}(4,790)=18.85, \mathrm{p}<$ .001). Thus, the pattern of EMG activation for the ECR revealed that not only was it overall greater for brushstroke- than pointillist-like painting, but also it was differently modulated for the two styles during the movement. Polynomial contrasts revealed a significant quadratic trend while participants were painting with a pointillist-like style $(\mathrm{F}(1,790)=$ $8.5, p=.004$ ), whereas the other trends were not significant (all $\mathrm{F}$ $(1,790)<1)$. Crucially, for the brushstroke-like style, polynomial contrasts revealed that both quadratic and cubic trends were significant (polynomial quadratic contrast: $\mathrm{F}(1,790)=202.25$, $\mathrm{p}<.001$; polynomial cubic contrast: $\mathrm{F}(1,790)=11.51, \mathrm{p}<.001$ ), while the linear trend was not significant $(\mathrm{F}(1,790)=1.93, p=.164)$. Thus, while the pattern of ECR activation followed an inverted U-shaped curve during pointillist-like painting, peaking at the brush-paper touch and decreasing soon after, the activation during brushstroke-like painting was partially maintained after the brush-paper contact and during stroking. Accordingly, planned comparisons between the two styles at each bin revealed that the two styles did not differ at the first bin (F $(1,790)=1.98, p=.159)$, while the ECR muscle activation was higher during brushstroke-like than pointillist-like style painting from the second up to the last bin (all $\mathrm{F}(1,790)>13.99$, $\mathrm{p}<.001$ ).

\section{Discussion}

The present study aimed to determine whether activation of an observer's motor cortex during the passive observation of artwork represents a non-specific emotional response (known to physiologically correspond to an early and non-muscle-specific modulation of CSE), or whether it rather reflects the simulation of the artist's movements when creating the observed artwork (known to correspond to a late musclespecific modulation of CSE). In order to address these questions, we asked participants to provide liking ratings for pointillist- or brushstroke-style paintings while, as a proxy of the activation of the observer's motor cortex, we recorded MEPs from muscles differently a)

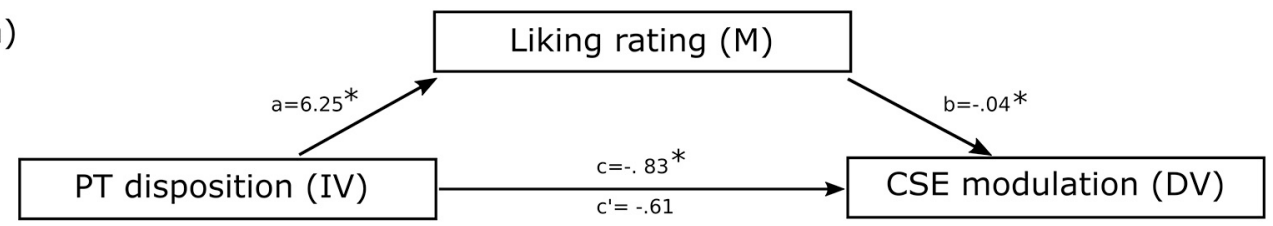

b)

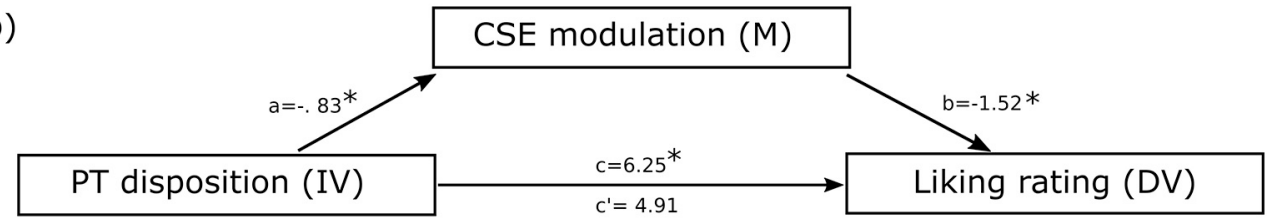

c)

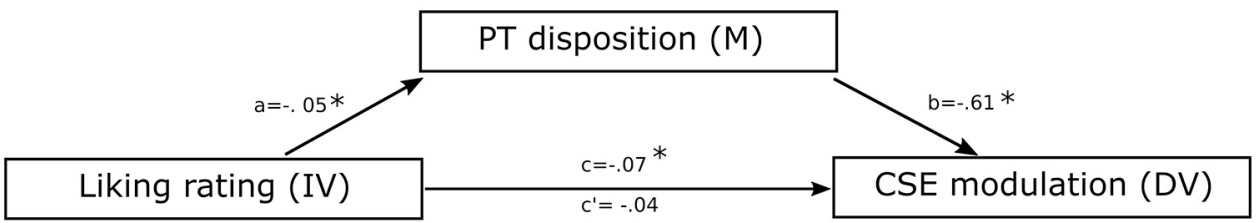

d)

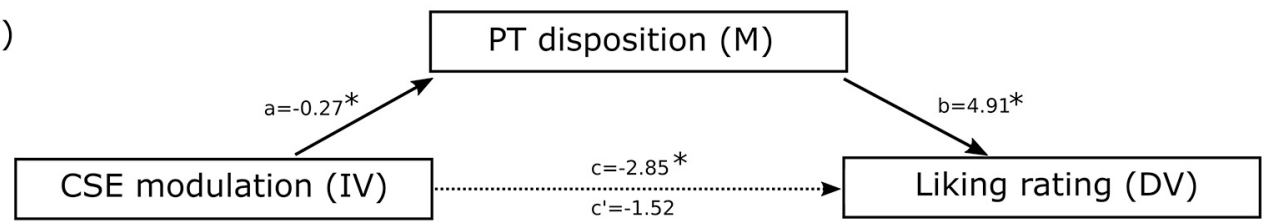

Fig. 5. Mediation models.

Four Mediation analyses were performed to test whether the influence of an independent variable (IV) on a dependent variable (DV) could be accounted for or not by a mediator (M). In particular we tested: a) the mediation of liking ratings $(\mathrm{M})$ in the influence of Perspective Taking (PT) dispositions (IV) on cortico-spinal excitability (CSE) modulation (DV); b) the mediation of CSE modulation (M) in the influence of PT dispositions (IV) on liking ratings (DV); c) the mediation of PT dispositions (M) in the influence of liking ratings (IV) on CSE modulation (DV); and d) the mediation of PT dispositions (M) in the influence of CSE modulation (IV) on liking ratings (DV). For each path (i.e., a, b, and c), values correspond to the unstandardized path coefficients. The indirect effect of the mediator (i.e., path c') was quantified as the difference between the unstandardized path coefficients of the direct effect between the independent and the dependent variables (i. e., path c) and the product of the unstandardized path coefficients (i.e., $\mathrm{a} \times \mathrm{b}$ ). Asterisks denote significant regression coefficients. Significant difference between the direct and the indirect effect (i.e., c vs c') is shown as dashed line (model d). 


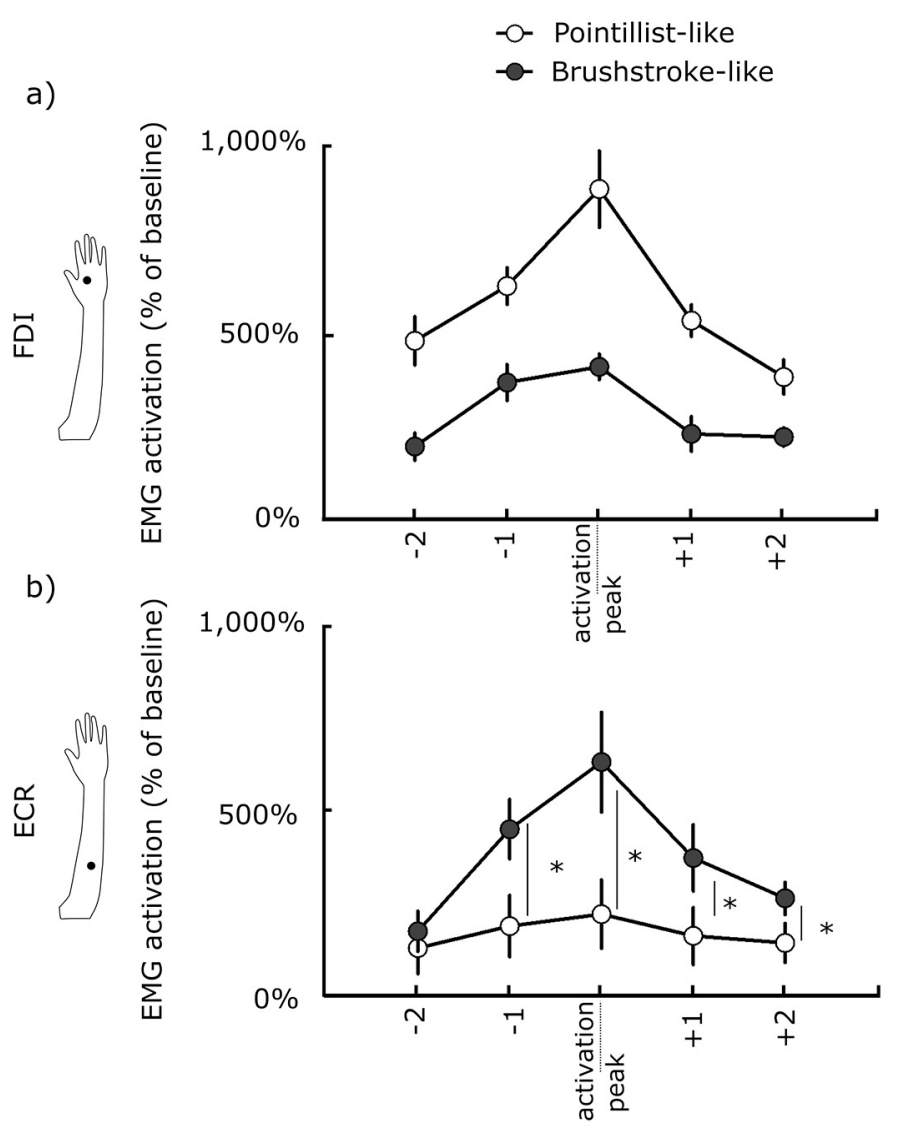

Fig. 6. Results of the control experiment.

The mean value of the electromyography (EMG) rectified signal, expressed as percent of baseline, recorded from the right first dorsal interosseous (FDI; a) and extensor carpi radialis (ECR; b) muscles during the execution of painting with pointillist- (white circles) and brushstroke-like (black circles) movements (Control experiment). The EMG signal was averaged in 200-ms bins and the 5 bins around the activation peak (dotted vertical line) were analyzed. Error bars indicate the standard error of the mean; asterisks indicate significant difference for the style $\times$ bin interaction, which was significant for the ECR muscle only. Rather, the main effects of style and bin were significant for both the FDI and the ECR muscles, revealing that the FDI was more engaged for pointillist-like painting and the ECR for brushstroke-like painting.

involved in the two painting styles: the right index finger (FDI) and forearm (ECR) muscles. spTMS was applied at 150 (i.e., early) or $300 \mathrm{~ms}$ (i.e., late) to record MEPs after the stimulus presentation. The results revealed a late and muscle-specific activation in response to passive viewing of canvases painted with the brushstroke style, suggesting that motor activation during artwork perception reflects a motor simulation response rather than a general emotional reaction.

Further detailing the results, the pattern of CSE modulation during artwork perception showed that observing brushstroke paintings increased ECR, but not FDI activation at the late delay post-stimulus presentation. This activation is unlikely due to a general motor response induced by viewing a complex stimulus as we tested only the modulation for viewing a painting, and controlled for the effect of viewing a comparably complex stimulus, such as a garden photographs. Nor can this modulation be due to viewing a valenced stimulus as it clearly differentiated the two muscles and the two painting styles, despite the two styles received comparable liking ratings. This does not mean that the observer's motor cortex is not involved in processing the emotional valence of a stimulus (Borgomaneri et al., 2015; Borgomaneri, Gazzola, \& Avenanti, 2012; Van den Stock et al., 2011), but rather that the late-timing and muscle-specific activation we found for brushstroke paintings is more compatible with a motor simulation than emotional processing response (Borgomaneri et al., 2015).

Indeed, the recording of the ECR activation in a control experiment, while a separate group of individuals actually executed painting movements, showed that the ECR was not only more activated for brushstroke- than pointillist-like movements, but it also showed a differential modulation for the different phases of the movement. In particular, while the ECR activation during brushstroke-like movements peaked at the brush-paper contact, its differential activation as compared to pointillist-like movements was kept also during the stroking phase. This suggests that ECR activation plays a specific role in producing the strokes and not only in grasping and holding the brush, at least when participants are instructed to perform these movements by holding the brush with a power grasp. Notably, given that the same instructions were provided in the visuomotor training before the TMS session, it is likely that a similar muscle-specific involvement for the two painting styles was triggered in the participants of the main experiment during the visuomotor training. Conversely, even if the FDI was more activated during pointillist- than brushstroke-like movements, its differential activation was not modulated during the movement, suggesting a more general role in grasping and holding the brush rather than in producing the dots. This may explain why we did not observe a specific FDI CSE modulation during observation of pointillist paintings and suggests that the pattern of motor activation during artwork perception may specifically match the functionally relevant aspects of the movements. In other words, what is simulated in the motor cortex of an artwork beholder is not simply the act of grasping the brush, but the act of tracing the canvas with a brush.

Similar muscle-specific CSE modulation has been previously reported during artwork perception. Battaglia, Lisanby, \& Freedberg, 2011 recorded MEPs from the ECR muscle while participants observed pictures of Michelangelo's "Expulsion from Paradise" fresco, which depicts a hand extension movement, and compared MEPs to those recorded during the observation of a real hand photographed in the same pose or another painting depicting relaxed or flexed hands (Michelangelo's "Creation of Adam" or Bellini's "Dead Christ with Angels"). They found that the CSE was more facilitated during the observation of the "Expulsion from Paradise" as compared to all other stimuli. However, it seems reasonable to argue that motor activation during painting perception in the Battaglia, Lisanby, \& Freedberg, 2011's study reflected the motor simulation of the movement depicted within it, rather than the movement implied to produce it. Here, we selected stimuli that did not depict any human figure or body part to isolate a possible simulation of the artist's movements or the emotional processing of the stimuli (which we excluded with the time- and muscle-specificity of the activation profile) from the representational content.

The activation of the motor cortex for abstract artworks without representational content has been explored using EEG (Umilta, Berchio, Sestito, Freedberg, \& Gallese, 2012) and ERPs (Sbriscia-Fioretti et al., 2013). In particular, Umilta, Berchio, Sestito, Freedberg, \& Gallese, 2012 showed greater mu-rhythm suppression (an index of motor activation) during passive viewing of Lucio Fontana's slashed canvases, which are readily evocative of the artist's action to cut the canvas, as compared to the observation of graphically modified versions of the same artwork. Similarly, Sbriscia-Fioretti et al. (2013) found that passive viewing of Franz Kline's paintings (depicting geometrical brushstrokes), as compared to modified versions of the same forms, evoked a greater fronto-central deflection of ERPs at around $300 \mathrm{~ms}$ post-stimulus onset at an interval corresponding to our late spTMS. All in all, our findings corroborate previous evidence of motor activation in response to the observation of artworks. Capitalizing on the muscle and time specificity of spTMS-MEP recording, we were also able to show that this motor activation specifically reflects the simulation of the motoric aspects of the artist's painting acts and differentiate it from an emotional response.

Importantly, this action-specific modulation of motor activation was lower in those individuals who liked the paintings more and who tended 
to more easily take the cognitive perspective of others (as measured by the PT of the IRI). Dispositional empathy was also positively correlated with the liking ratings. Thus, the less the participants' motor cortex was activated during the observation of canvases, the more they liked the canvases, and the more they were attuned to "put themselves into others' shoes". All together, these findings provide clear evidence for an association between aesthetic experience, empathy, and motor response during artwork perception (Freedberg \& Gallese, 2007; Ticini, Urgesi, \& Calvo-Merino, 2015). The positive influence of dispositional empathy on aesthetic appreciation is in line with previous empirical studies (Garrido \& Schubert, 2011; Kawakami \& Katahira, 2015; Vuoskoski, Thompson, McIlwain, \& Eerola, 2012) and fits well with the embodied aesthetics claim (Freedberg \& Gallese, 2007) that "putting oneself into the artist's shoes" is a crucial aspect of aesthetic experience. However, what might appear surprising here is that both liking ratings and dispositional empathy were associated with lower motor activation during canvas perception. Indeed, both the embodied aesthetics account (Freedberg \& Gallese, 2007) and previous evidence of motor activation during artwork perception (Battaglia, Lisanby, \& Freedberg, 2011; SbrisciaFioretti et al., 2013; Umilta, Berchio, Sestito, Freedberg, \& Gallese, 2012) would suggest that greater motor activation correlates with higher aesthetic appreciation as higher simulation would lead to greater liking. However, if the relation between motor activation, simulation, and aesthetic experience was merely linear, how could most of us appreciate the complex and irreproducible moves of dancers, contortionists, or musicians even being unable to produce the same performance? In this sense, one may consider that, if our findings support the involvement of motor simulation in aesthetic experience, they do not fit with a linear relationship between the extent of motor activation or readiness of motor simulation and aesthetic appreciation (Gardner, Goulden, \& Cross, 2015; Kirsch \& Cross, 2018; Kirsch, Dawson, \& Cross, 2015; Kirsch, Drommelschmidt, \& Cross, 2013).

While it is widely known that expertise with an observed movement boosts the extent (Calvo-Merino, Glaser, Grèzes, Passingham, \& Haggard, 2005; Calvo-Merino, Grèzes, Glaser, Passingham, \& Haggard, 2006; Cross, Hamilton, \& Grafton, 2006; Kirsch \& Cross, 2015) and selectivity (Aglioti, Cesari, Romani, \& Urgesi, 2008) of motor activation, several studies have provided evidence of an even greater motor activation in response to actions that are farther from the observer's motor repertoire, for example in the case of biomechanically impossible (Romani, Cesari, Urgesi, Facchini, \& Aglioti, 2005), robotic (Cross et al., 2012; Grossmann, Cross, Ticini, \& Daum, 2013), contortionist (Cross, Mackie, Wolford, de C Hamilton, \& Hamilton, 2010), or residual limb (Aziz-Zadeh, Sheng, Liew, \& Damasio, 2012) movements. In all these cases, rather than reflecting the ease of simulation, motor activation seems to reflect the attempt to match unusual or completely new movements with known motor representations.

Considering brain activations associated to aesthetic experience, greater activation of occipital and premotor cortex was obtained in expert dancers during the viewing of dance moves that were judged as being more pleasant (Calvo-Merino, Jola, Glaser, \& Haggard, 2008). Furthermore, reminding the effects of performing pointillist- and brushstroke-like movements on the aesthetic appreciation of canvases (Leder et al., 2012), visual (Jola, Abedian-Amiri, Kuppuswamy, Pollick, \& Grosbras, 2012; Orgs, Hagura, \& Haggard, 2013), and physical (Kirsch, Drommelschmidt, \& Cross, 2013; Kirsch, Dawson, \& Cross, 2015) training with dance moves increased aesthetic appreciation and sensorimotor activations during observation of the same moves. These findings are consistent with the notion that the ease of simulation of artistic performance is a crucial aspect of aesthetic experiences. However, greater activation of visual and sensorimotor areas has been also reported in non-dancer participants when viewing dance moves that they liked more and judged as more difficult to physically reproduce (Cross, Kirsch, Ticini, \& Schütz-Bosbach, 2011). This points to what has been referred to as "Cirque du Soleil effect", where we may enjoy witnessing the spectacular movements of talented performers that are more "unlike us" and, thus, do not belong and cannot be incorporated into our sensorimotor repertoire (Cross, Kirsch, Ticini, \& Schütz-Bosbach, 2011; Kirsch, Urgesi, \& Cross, 2015). Converging evidence for such an "unlike me" aspect of aesthetic experience has come from studies using brain stimulation methods to modulate activation of motor areas during aesthetic experience (reviewed in Cattaneo, 2020; Kirsch, Urgesi, \& Cross, 2015). Indeed, these studies have shown that lowering motor activation with inhibitory stimulation of fronto-parietal motor areas may be associated to greater aesthetic appreciation of natural stimuli, such as dance movies (Calvo-Merino, Urgesi, Orgs, Aglioti, \& Haggard, 2010) and static or dynamic body postures (Cazzato, Mele, \& Urgesi, 2016), artifacts (Ticini, Urgesi, \& Kotz, 2017)() or artworks (Nakamura \& Kawabata, 2015).

However, this is not necessarily in contrast with an embodied simulation account of aesthetics as what counts in aesthetic experience might not be the ease of simulation or embodiment of the movement depicted or implied in a piece of art, but the attempt to simulate/embody it (Kirsch, Urgesi, \& Cross, 2015). In this sense, motor activation during artwork perception might reflect the attempt to incorporate a more or less familiar movement into the motor repertoire of the beholder. Whatever is the result of this process, either a full match in the motor repertoire of an expert or a sublime mismatch in the motor repertoire of a naïve beholder, it heightens aesthetic experience. This suggestion was corroborated by the applied mediation analysis, which showed that participants' ability to take the cognitive perspective of others was a significant mediator that at least partially explained the effect of muscleselective motor activation on liking ratings. Indeed, while we did not find evidence that the relation between perspective taking and liking ratings was mediated by the extent of motor activation, lower motor activation led to higher liking ratings especially in those individuals who reported higher disposition to take the cognitive perspective of others. Accordingly, it has been shown that higher disposition to perspective taking facilitates the embodiment of unlike-me movements, such as the movements of the residual limb of an amputee person (Liew, Sheng, \& Aziz-Zadeh, 2013) or of the pain inflicted to stranger's body (Avenanti, Minio-Paluello, Bufalari, \& Aglioti, 2009). Furthermore, perspectivetaking disposition was also associated with the increase of the aesthetic appreciation of objects after interferential stimulation over the observer's parietal cortex (Ticini, Urgesi, \& Kotz, 2017)(). Crucially, the effect of empathic dispositions may be attenuated by experience (Liew et al., 2013), pointing to an interaction between individual dispositional traits and actual experience in shaping the way we simulate and embody others (Kirsch, Urgesi, \& Cross, 2015).

It is worth noting that our participants were quite naïve to art as documented by their scores on the Art Experience Questionnaire. Moreover, their attempt to produce pointillist- or brushstroke-like drawings in the preliminary visuomotor training served us to ensure an association between pointillist- or brushstroke-style paintings and, respectively, stippling or stroking movements. However, this might have also exacerbated the distance between the participant's graphical skills and those of the famous Neo-Impressionist or Post-impressionist painters. Different forms of Arts, for example Lucio Fontana's cuts (Umilta, Berchio, Sestito, Freedberg, \& Gallese, 2012) or Franz Kline's graphical marks (Sbriscia-Fioretti et al., 2013), may trigger an easier embodiment or the artist's movements in the beholders' motor repertoire. Our findings of a negative relation between motor activation and liking ratings of representational canvases may not extend to the appreciation of other forms of art, which may differently yet powerfully trigger aesthetic experiences with different processes. Future studies are required to further clarify the influence of visuomotor experience and skills and forms of art in modulating the extent of motor activation during aesthetic appreciation (Leder et al., 2012; Ticini, Rachman, Pelletier, \& Dubal, 2014). In this regard, we acknowledge that the specific pattern of muscle-specific modulation of CSE during the observation of brushstroke-like canvases might have been biased by the visuomotor training participants received prior to the TMS session. This training allowed ensuring specific 
associations between different painting styles and different brush grasping strategies, thus reducing expected inter-individual variability in motor strategies during painting, which has been shown to shape sensorimotor activity during action observation (Hilt et al., 2020). The control experiment highlighted the specific involvement of the two muscles in the two different grasp and paint strategies. However, this may hinder the generalizability of our results to other conditions. Different results could arise from an experimental design in which no explicit visuomotor associations are established or when dealing with art-experienced individuals.

Finally, the multifaceted nature of aesthetic experience cannot be easily grasped by a subjective, explicit liking judgment as used in the present and (many other) neuroscientific studies (Calvo-Merino et al., 2008; Kirsch, Urgesi, \& Cross, 2015), thus urging caution in generalizing the role of motor activation, simulation and empathy to the various facets of aesthetic experience. Nevertheless, our finding of a late and muscle-selective activation of the observer's motor system during perception of paintings suggests that the motor involvement in artwork perception reflects motor simulation and not simply an emotional reactivity response. This converges with previous studies (Ardizzi et al., 2020; Sbriscia-Fioretti et al., 2013; Umilta, Berchio, Sestito, Freedberg, $\&$ Gallese, 2012) in showing that action simulation and embodiment are crucial aspects of aesthetic experience.

\section{CRediT authorship contribution statement}

Alessandra Finisguerra: Methodology, Investigation, Data curation, Formal analysis, Funding acquisition, Writing - original draft. Luca F. Ticini: Conceptualization, Methodology, Investigation, Writing - review \& editing. Louise P. Kirsch: Methodology, Writing - review \& editing. Emily S. Cross: Conceptualization, Methodology, Writing - review \& editing. Sonja A. Kotz: Conceptualization, Writing - review \& editing. Cosimo Urgesi: Conceptualization, Methodology, Investigation, Data curation, Formal analysis, Funding acquisition, Writing original draft.

\section{Funding}

This work was supported by grants from the Italian Ministry of University and Research (PRIN 2017, Prot. 2017N7WCLP; to CU), and from the Italian Ministry of Health (Ricerca Corrente 2020, Scientific Institute, IRCCS E. Medea; to AF).

\section{Data reference}

The file with the data for this study is available at https://osf. io/8kpx7.

\section{Acknowledgements}

We thank Valentina Cazzato and Walter Fantuz for help in stimulus selection and Simone Battaglia for help in preliminary data collection.

\section{References}

Aglioti, S. M., Cesari, P., Romani, M., \& Urgesi, C. (2008). Action anticipation and motor resonance in elite basketball players. Nature Neuroscience, 11(9), 1109-1116. https://doi.org/10.1038/nn.2182.

Amoruso, L., \& Finisguerra, A. (2019). Low or high-level motor coding? The Role of Stimulus Complexity. Frontiers in Human Neuroscience, 13(October), 1-9. https://doi. org/10.3389/fnhum.2019.00332, 332.

Ardizzi, M., Ferroni, F., Siri, F., Umiltà, M. A., Cotti, A., Calbi, M., ... Gallese, V. (2020). Beholders' sensorimotor engagement enhances aesthetic rating of pictorial facial expressions of pain. Psychological Research, 84(2), 370-379. https://doi.org/ 10.1007/s00426-018-1067-7.

Armony, J. L., \& Dolan, R. J. (2002). Modulation of spatial attention by fear-conditioned stimuli: An event-related fMRI study. Neuropsychologia, 40(7), 817-826. https://doi. org/10.1016/S0028-3932(01)00178-6.
Avenanti, A., Candidi, M., \& Urgesi, C. (2013). Vicarious motor activation during action perception: Beyond correlational evidence. Frontiers in Human Neuroscience, 7(May), 1-8. https://doi.org/10.3389/fnhum.2013.00185, 185.

Avenanti, A., Minio-Paluello, I., Bufalari, I., \& Aglioti, S. M. (2009). The pain of a model in the personality of an onlooker: Influence of state-reactivity and personality traits on embodied empathy for pain. NeuroImage, 44(1), 275-283. https://doi.org/ 10.1016/j.neuroimage.2008.08.001.

Aziz-Zadeh, L., Sheng, T., Liew, S.-L., \& Damasio, H. (2012). Understanding otherness: The neural bases of action comprehension and pain empathy in a congenital amputee. Cerebral Cortex, 22(4), 811-819. https://doi.org/10.1093/cercor/bhr139.

Battaglia, F., Lisanby, S. H., \& Freedberg, D. (2011). Corticomotor excitability during observation and imagination of a work of art. Frontiers in Human Neuroscience, 5 (August), 1-6. https://doi.org/10.3389/fnhum.2011.00079, 79.

Borgomaneri, S., Gazzola, V., \& Avenanti, A. (2012). Brain stimulation. Brain Stimulation, 5(2), 70-76. https://doi.org/10.1016/j.brs.2012.03.011.

Borgomaneri, S., Gazzola, V., \& Avenanti, A. (2015). Transcranial magnetic stimulation reveals two functionally distinct stages of motor cortex involvement during perception of emotional body language. Brain Structure and Function, 220(5), 2765-2781. https://doi.org/10.1007/s00429-014-0825-6.

Boukarras, S., Era, V., Aglioti, S. M., \& Candidi, M. (2020). Modulation of preference for abstract stimuli following competence-based social status primes. Experimental Brain Research, 238(1), 193-204. https://doi.org/10.1007/s00221-019-05702-z.

Calvo-Merino, B., Glaser, D. E., Grèzes, J., Passingham, R. E., \& Haggard, P. (2005). Action observation and acquired motor skills: An FMRI study with expert dancers. Cerebral Cortex, 15(8), 1243-1249. https://doi.org/10.1093/cercor/bhi007.

Calvo-Merino, B., Grèzes, J., Glaser, D. E., Passingham, R. E., \& Haggard, P. (2006). Seeing or doing? Influence of visual and motor familiarity in action observation. Current Biology, 16(19), 1905-1910. https://doi.org/10.1016/j.cub.2006.07.065.

Calvo-Merino, B., Jola, C., Glaser, D. E. E., \& Haggard, P. (2008). Towards a sensorimotor aesthetics of performing art. Consciousness and Cognition, 17(3), 911-922. https:// doi.org/10.1016/j.concog.2007.11.003.

Calvo-Merino, B., Urgesi, C., Orgs, G., Aglioti, S. M. S. M., \& Haggard, P. (2010). Extrastriate body area underlies aesthetic evaluation of body stimuli. Experimental Brain Research, 204(3), 447-456. https://doi.org/10.1007/s00221-010-2283-6.

Cattaneo, Z. (2020). Neural correlates of visual aesthetic appreciation: Insights from noninvasive brain stimulation. Experimental Brain Research, 238(1), 1-16. https://doi. org/10.1007/s00221-019-05685-X.

Cazzato, V., Mele, S., \& Urgesi, C. (2016). Different contributions of visual and motor brain areas during liking judgments of same- and different-gender bodies. Brain Research, 1646, 98-108. https://doi.org/10.1016/j.brainres.2016.05.047.

Cela-Conde, C. J., Ayala, F. J., Munar, E., Maestú, F., Nadal, M., \& Capó, M. a, ... Marty, G.. (2009). Sex-related similarities and differences in the neural correlates of beauty. Proceedings of the National Academy of Sciences of the United States of America, 106 (10), 3847-3852. https://doi.org/10.1073/pnas.0900304106.

Chatterjee, A., \& Vartanian, O. (2014). Neuroaesthetics. Trends in Cognitive Sciences, 18 (7), 370-375. https://doi.org/10.1016/j.tics.2014.03.003.

Chatterjee, A., Widick, P., Sternschein, R., Smith, W. B., \& Bromberger, B. (2010). The assessment of art attributes. Empirical Studies of the Arts, 28(2), 207-222. https://doi. org/10.2190/EM.28.2.f.

Chen, R., Classen, J., Gerloff, C., Celnik, P., Wassermann, E. M., Hallett, M., \& Cohen, L. G.Â. (1997). Depression of motor cortex excitability by low-frequency transcranial magnetic stimulation. Neurology, 48(5), 1398-1403. https://doi.org/ 10.1212/wnl.48.5.1398.

Cook, R. D., \& Weisberg, S. (1983). Diagnostics for heteroscedasticity in regression. Biometrika, 70(1), 1-10. https://doi.org/10.1093/biomet/70.1.1.

Cross, E. S., Hamilton, A. F. D. C., \& Grafton, S. T. (2006). Building a motor simulation de novo: Observation of dance by dancers. NeuroImage, 31(3), 1257-1267. https://doi. org/10.1016/j.neuroimage.2006.01.033.

Cross, E. S., Kirsch, L. P., Ticini, L. F., \& Schütz-Bosbach, S. (2011). The impact of aesthetic evaluation and physical ability on dance perception. Frontiers in Human Neuroscience, 5(September), 1-10. https://doi.org/10.3389/fnhum.2011.00102, 102.

Cross, E. S., Liepelt, R., Hamilton, A. F. D. C., Parkinson, J., Ramsey, R., Stadler, W., ... de C Hamilton, A. F.. (2012). Robotic movement preferentially engages the action observation network. Human Brain Mapping, 33(9), 2238-2254. https://doi.org/ 10.1002/hbm.21361.

Cross, E. S., Mackie, E. C., Wolford, G., de C Hamilton, A. F., \& Hamilton, A. F. D. C. (2010). Contorted and ordinary body postures in the human brain. Experimental Brain Research, 204(3), 397-407. https://doi.org/10.1007/s00221-009-2093-x.

Devanne, H., Lavoie, B. A., \& Capaday, C. (1997). Input-output properties and gain changes in the human corticospinal pathway. Experimental Brain Research, 114(2), 329-338. https://doi.org/10.1007/PL00005641.

Di Dio, C., \& Gallese, V. (2009). Neuroaesthetics: a review. Current Opinion in Neurobiology, 19(6), 682-687. https://doi.org/10.1016/j.conb.2009.09.001. December.

Di Dio, C., Macaluso, E., \& Rizzolatti, G. (2007). The golden beauty: Brain response to classical and renaissance sculptures. PLoS One, 2(11), Article e1201. https://doi.org/ 10.1371/journal.pone.0001201.

Duncan, D. (1955). Multiple range and multiple F tests. Biometrics, 11(1), 1-42. https:// doi.org/10.2307/3001478.

Dunnett, C. W. (1970). Query: Multiple comparison tests. Biometrics, 26(1), 139-141. https://doi.org/10.2307/2529050.

Era, V., Candidi, M., \& Aglioti, S. M. (2015). Subliminal presentation of emotionally negative vs positive primes increases the perceived beauty of target stimuli. Experimental Brain Research, 233(11), 3271-3281. https://doi.org/10.1007/s00221015-4395-5. 
Era, V., Candidi, M., \& Aglioti, S. M. (2019). Contextual and social variables modulate aesthetic appreciation of bodily and abstract art stimuli. Acta Psychologica, 199 (December 2018), 102881. https://doi.org/10.1016/j.actpsy.2019.102881.

Fadiga, L., Craighero, L., \& Olivier, E. (2005). Human motor cortex excitability during the perception of others' action. Current Opinion in Neurobiology, 15(2), 213-218. https://doi.org/10.1016/j.conb.2005.03.013.

Faul, F., Erdfelder, E., Lang, A.-G., \& Buchner, A. (2007). G*power: A flexible statistical power analysis program for the social, behavioral, and biomedical sciences. Behavior Research Methods, 39(2), 175-191. https://doi.org/10.3758/BF03193146.

Freedberg, D., \& Gallese, V. (2007). Motion, emotion and empathy in esthetic experience. Trends in Cognitive Sciences, 11(5), 197-203. https://doi.org/10.1016/j. tics.2007.02.003.

Gardner, T., Goulden, N., \& Cross, E. S. (2015). Dynamic modulation of the action observation network by movement familiarity. Journal of Neuroscience, 35(4), 1561-1572. https://doi.org/10.1523/JNEUROSCI.2942-14.2015.

Garrido, S., \& Schubert, E. (2011). Individual differences in the enjoyment of negative emotion in music: A literature review and experiment. Music Perception, 28(3), 279-295. https://doi.org/10.1525/MP.2011.28.3.279.

Gentilucci, M., Bernardis, P., Crisi, G., \& Dalla Volta, R. (2006). Repetitive transcranial magnetic stimulation of Broca's area affects verbal responses to gesture observation. Journal of Cognitive Neuroscience, 18(7), 1059-1074. https://doi.org/10.1162/ jocn.2006.18.7.1059.

Gernot, G., Pelowski, M., \& Leder, H. (2018). Empathy, Einfühlung, and aesthetic experience: The effect of emotion contagion on appreciation of representational and abstract art using fEMG and SCR. Cognitive Processing, 19(2), 147-165. https://doi. org/10.1007/s10339-017-0800-2.

Goodman, L. A. (1960). On the exact variance of products. Journal of the American Statistical Association, 55(292), 708-713. https://doi.org/10.1080/ 01621459.1960 .10483369$.

Grossmann, T., Cross, E. S., Ticini, L. F., \& Daum, M. M. (2013). Action observation in the infant brain: The role of body form and motion. Social Neuroscience, 8(1), 22-30. https://doi.org/10.1080/17470919.2012.696077.

Heimann, K., Uithol, S., Calbi, M., Umiltà, M. A., Guerra, M., Fingerhut, J., \& Gallese, V. (2019). Embodying the camera: An EEG study on the effect of camera movements on film spectators' sensorimotor cortex activation. PLoS One, 14(3), 1-18. https://doi. org/10.1371/journal.pone.0211026.

Hilt, P. M., Cardellicchio, P., Dolfini, E., Pozzo, T., Fadiga, L., \& D’Ausilio, A. (2020). Motor recruitment during action observation: Effect of interindividual differences in action strategy. Cerebral Cortex, 30(7), 3910-3920. https://doi.org/10.1093/cercor/ bhaa006.

Editor IJSMI. (2016). Post-hoc and multiple comparison test - An overview with SAS and R statistical package. International Journal of Statistics and Medical Informatics, 1(1), 1-9. https://doi.org/10.3000/IJSMI.V1I1.4.

Jola, C., Abedian-Amiri, A., Kuppuswamy, A., Pollick, F. E., \& Grosbras, M. H. (2012). Motor simulation without motor expertise: Enhanced corticospinal excitability in visually experienced dance spectators. PLoS One, 7(3). https://doi.org/10.1371/ journal.pone. 0033343.

Kawabata, H., \& Zeki, S. (2004). Neural correlates of beauty. Journal of Neurophysiology, 91(4), 1699-1705. https://doi.org/10.1152/jn.00696.2003.

Kawakami, A., \& Katahira, K. (2015). Influence of trait empathy on the emotion evoked by sad music and on the preference for it. Frontiers in Psychology, 6(October), 1-9. https://doi.org/10.3389/fpsyg.2015.01541.

Kirsch, L. P., \& Cross, E. S. (2015). Additive routes to action learning: Layering experience shapes engagement of the action observation network. Cerebral Cortex, 25 (12), 4799-4811. https://doi.org/10.1093/cercor/bhv167.

Kirsch, L. P., \& Cross, E. S. (2018). The influence of sensorimotor experience on the aesthetic evaluation of dance across the life span. In (1st ed.), vol. 237. Progress in Brain Research. Elsevier B.V. https://doi.org/10.1016/bs.pbr.2018.03.012.

Kirsch, L. P., Dawson, K., \& Cross, E. S. (2015). Dance experience sculpts aesthetic perception and related brain circuits. Annals of the New York Academy of Sciences, 1337(1), 130-139. https://doi.org/10.1111/nyas.12634.

Kirsch, L. P., Drommelschmidt, K. A., \& Cross, E. S. (2013). The impact of sensorimotor experience on affective evaluation of dance. Frontiers in Human Neuroscience, 7 (September), 1-10. https://doi.org/10.3389/fnhum.2013.00521, 521.

Kirsch, L. P., Urgesi, C., \& Cross, E. S. (2015). The shaping and reshaping of the aesthetic brain: Emerging perspectives on the neurobiology of embodied aesthetics. Neuroscience and Biobehavioral Reviews, 62, 56-68. https://doi.org/10.1016/j. neubiorev.2015.12.005.

Leder, H., Bär, S., \& Topolinski, S. (2012). Covert painting simulations influence aesthetic appreciation of artworks. Psychological Science, 23(12), 1479-1481. https://doi.org/10.1177/0956797612452866.

Lepage, J. F., Tremblay, S., \& Théoret, H. (2010). Early non-specific modulation of corticospinal excitability during action observation. European Journal of Neuroscience, 31(5), 931-937. https://doi.org/10.1111/j.1460-9568.2010.07121.x.

Liew, S. L., Sheng, T., \& Aziz-Zadeh, L. (2013). Experience with an amputee modulates one's own sensorimotor response during action observation. NeuroImage, 69, 138-145. https://doi.org/10.1016/j.neuroimage.2012.12.028.

Loporto, M., Holmes, P. S., Wright, D. J., \& McAllister, C. J. (2013). Reflecting on Mirror mechanisms: Motor resonance effects during action observation only present with low-intensity Transcranial magnetic stimulation. PLoS One, 8(5), Article e64911. https://doi.org/10.1371/journal.pone.0064911.

Lutz, A., Nassehi, A., Bao, Y., Pöppel, E., Sztrókay, A., Reiser, M., ... Gutyrchik, E. (2013). Neurocognitive processing of body representations in artistic and photographic images. NeuroImage, 66, 288-292. https://doi.org/10.1016/j. neuroimage.2012.10.067.
MacKinnon, D. P., Warsi, G., \& Dwyer, J. H. (1995). A simulation study of mediated effect measures. Multivariate Behavioral Research, 30(1), 41-62. https://doi.org/ 10.1207/s15327906mbr3001_3.

McHugh, M. L. (2011). Multiple comparison analysis testing in ANOVA. Biochemia Medica, 21(2), 203-209. https://doi.org/10.11613/BM.2011.029.

Naish, K. R., Houston-Price, C., Bremner, A. J., \& Holmes, N. P. (2014). Effects of action observation on corticospinal excitability: Muscle specificity, direction, and timing of the mirror response. Neuropsychologia, 64, 331-348. https://doi.org/10.1016/j. neuropsychologia.2014.09.034. Elsevier.

Nakamura, K., \& Kawabata, H. (2015). Transcranial direct current stimulation over the medial prefrontal cortex and left primary motor cortex (mPFC-lPMC) affects subjective beauty but not ugliness. Frontiers in Human Neuroscience, 9(December), 1-8. https://doi.org/10.3389/fnhum.2015.00654, 654.

Oldfield, R. C. (1971). The assessment and analysis of handedness: The Edinburgh inventory. Neuropsychologia, 9(1), 97-113. https://doi.org/10.1016/0028-3932(71) 90067-4.

Orgs, G., Hagura, N., \& Haggard, P. (2013). Learning to like it: Aesthetic perception of bodies, movements and choreographic structure. Consciousness and Cognition, 22(2), 603-612. https://doi.org/10.1016/j.concog.2013.03.010.

Osborne, J. W. (2003). Notes on the use of data transformations. Practical Assessment, Research and Evaluation, 8(6), 1-7.

Pearce, M. T., Zaidel, D. W., Vartanian, O., Skov, M., Leder, H., Chatterjee, A., \& Nadal, M. (2016). Neuroaesthetics: The cognitive neuroscience of aesthetic experience. Perspectives on Psychological Science, 11(2), 265-279. https://doi.org/ $10.1177 / 1745691615621274$.

Prinz, W. (1997). Perception and action planning. European Journal of Cognitive Psychology, 9(2), 129-154. https://doi.org/10.1080/713752551.

Rizzolatti, G., \& Craighero, L. (2004). The mirror-neuron system. Annual Review of Neuroscience, 27, 169-192. https://doi.org/10.1146/annurev. neuro.27.070203.144230.

Romani, M., Cesari, P., Urgesi, C., Facchini, S., \& Aglioti, S. M. S. M. (2005). Motor facilitation of the human cortico-spinal system during observation of biomechanically impossible movements. NeuroImage, 26(3), 755-763. https://doi.org/ 10.1016/j.neuroimage.2005.02.027.

Rossi, S., Hallett, M., Rossini, P. M., \& Pascual-Leone, A. (2009). Safety, ethical considerations, and application guidelines for the use of transcranial magnetic stimulation in clinical practice and research. Clinical Neurophysiology, 120(12), 2008-2039. https://doi.org/10.1016/j.clinph.2009.08.016.

Rossini, P. M., Burke, D., Chen, R., Cohen, L. G., Daskalakis, Z., Di Iorio, R., Ziemann, U. (2015). Non-invasive electrical and magnetic stimulation of the brain, spinal cord, roots and peripheral nerves: Basic principles and procedures for routine clinical and research application: An updated report from an I.F.C.N. committee. Clinical Neurophysiology, 126(6), 1071-1107. https://doi.org/10.1016/j. clinph.2015.02.001.

Sarasso, P., Ronga, I., Pistis, A., Forte, E., Garbarini, F., Ricci, R., \& Neppi-Modona, M. (2019). Aesthetic appreciation of musical intervals enhances behavioural and neurophysiological indexes of attentional engagement and motor inhibition. Scientific Reports, 9(1), 1-14. https://doi.org/10.1038/s41598-019-55131-9.

Sbriscia-Fioretti, B., Berchio, C., Freedberg, D., Gallese, V., \& Umiltà, M. A. (2013). ERP modulation during observation of abstract paintings by Franz Kline. PLoS One, 8(10). https://doi.org/10.1371/journal.pone.0075241.

Tamietto, M., Castelli, L., Vighetti, S., Perozzo, P., Geminiani, G., Weiskrantz, L., \& de Gelder, B. (2009). Unseen facial and bodily expressions trigger fast emotional reactions. Proceedings of the National Academy of Sciences of the United States of America, 106(42), 17661-17666. https://doi.org/10.1073/pnas.0908994106.

Ticini, L. F., Rachman, L., Pelletier, J., \& Dubal, S. (2014). Enhancing aesthetic appreciation by priming canvases with actions that match the artist's painting style. Frontiers in Human Neuroscience, 8(June), 1-6. https://doi.org/10.3389/ fnhum.2014.00391, 391.

Tokimura, H., Tokimura, Y., Oliviero, A., Asakura, T., \& Rothwell, J. C. (1996). Speechinduced changes in corticospinal excitability. Annals of Neurology, 40(4), 628-634. https://doi.org/10.1002/ana.410400413.

Ticini, L. F., Urgesi, C., \& Calvo-Merino, B. (2015). Embodied aesthetics: Insight from cognitive neuroscience of performing arts. In A. Scarinzi (Ed.), Aesthetics and the Embodied Mind: Beyond Art Theory and the Cartesian Mind-Body Dichotomy (pp. 103-115). Dordrecht: Springer.

Ubaldi, S., Barchiesi, G., \& Cattaneo, L. (2013). Bottom-up and top-down Visuomotor responses to action observation. Cerebral Cortex, 25(4), 1032-1041. https://doi.org/ 10.1093/cercor/bht295.

Umilta, M. A., Berchio, C., Sestito, M., Freedberg, D., \& Gallese, V. (2012). Abstract art and cortical motor activation: An EEG study. Frontiers in Human Neuroscience, 6 (November), 1-9. https://doi.org/10.3389/fnhum.2012.00311, 311.

Urgesi, C., Candidi, M., Fabbro, F., Romani, M., \& Aglioti, S. M. S. M. (2006). Motor facilitation during action observation: Topographic mapping of the target muscle and influence of the onlooker's posture. The European Journal of Neuroscience, 23(9), 2522-2530. https://doi.org/10.1111/j.1460-9568.2006.04772.x.

Van den Stock, J., Tamietto, M., Sorger, B., Pichon, S., Grézes, J., \& de Gelder, B. (2011). Cortico-subcortical visual, somatosensory, and motor activations for perceiving dynamic whole-body emotional expressions with and without striate cortex (V1). Proceedings of the National Academy of Sciences of the United States of America, 108 (39), 16188-16193. https://doi.org/10.1073/pnas.1107214108.

Vartanian, O., \& Goel, V. (2004). Neuroanatomical correlates of aesthetic preference for paintings. Neuroreport, 15(5), 893-897. https://doi.org/10.1097/00001756200404090-00032. 
Vuoskoski, J. K., Thompson, W. F., McIlwain, D., \& Eerola, T. (2012). Who enjoys listening to sad music and why? Music Perception, 29(3), 311-317. https://doi.org/ 10.1525/mp.2012.29.3.311.

Xenakis, I., Arnellos, A., \& Darzentas, J. (2012). The functional role of emotions in aesthetic judgment. New Ideas in Psychology, 30(2), 212-226. https://doi.org/ 10.1016/j.newideapsych.2011.09.003.
Ticini, L. F., Urgesi, C., \& Kotz, S. A. (2017). Modulating mimetic preference with theta burst stimulation of the inferior parietal cortex. Frontiers in Psychology, 8(December), 1-8. https://doi.org/10.3389/fpsyg.2017.02101, 2101.

Xenakis, I., \& Arnellos, A. (2015). Aesthetics as an emotional activity that facilitates sense-making: Towards an enactive approach to aesthetic experience. Aesthetics and the Embodied Mind: Beyond Art Theory and the Cartesian Mind-Body Dichotomy (pp. 245-259). Dordrecht: Springer.

Davis, M. H. (1996). Empathy: A Social Psychological Approach. New York: Routledge. 